\title{
Underlying Mechanisms of Gene-Environment Interactions in Externalizing Behavior: A Systematic Review and Search for Theoretical Mechanisms
}

\author{
Joyce Weeland $^{1,3}$ - Geertjan Overbeek ${ }^{3}$ - Bram Orobio de Castro ${ }^{1}$ • \\ Walter Matthys ${ }^{2}$
}

Published online: 4 November 2015

(c) The Author(s) 2015. This article is published with open access at Springerlink.com

\begin{abstract}
Over the last decade, several candidate genes (i.e., MAOA, DRD4, DRD2, DAT1, 5-HTTLPR, and $C O M T$ ) have been extensively studied as potential moderators of the detrimental effects of postnatal family adversity on child externalizing behaviors, such as aggression and conduct disorder. Many studies on such candidate gene by environment interactions (i.e., $\mathrm{cG} \times \mathrm{E}$ ) have been published, and the first part of this paper offers a systematic review and integration of their findings $(n=53)$. The overview shows a set of heterogeneous findings. However, because of large differences between studies in terms of sample composition, conceptualizations, and power, it is difficult to determine if different findings indeed illustrate inconsistent $\mathrm{cG} \times \mathrm{E}$ findings or if findings are simply incomparable. In the second part of the paper, therefore, we argue that one way to help resolve this problem is the development of theory-driven a priori hypotheses on which biopsychosocial mechanisms might underlie $\mathrm{cG} \times \mathrm{E}$. Such a theoretically based approach can help us specify our research strategies, create more comparable findings, and help us interpret different findings between studies. In accordance, we describe three possible explanatory mechanisms, based on extant literature on the
\end{abstract}

Joyce Weeland

j.weeland@uva.nl

1 Utrecht Centre for Child and Adolescent Studies, Utrecht University, PO Box 15.804, 1001 NH Amsterdam, The Netherlands

2 Department of Child and Adolescent Studies, Utrecht University, Utrecht, The Netherlands

3 Present Address: Research Institute of Child Development and Education, University of Amsterdam, Amsterdam, The Netherlands concepts of (1) emotional reactivity, (2) reward sensitivity, and (3) punishment sensitivity. For each mechanism, we discuss the link between the putative mechanism and externalizing behaviors, the genetic polymorphism, and family adversity. Possible research strategies to test these mechanisms, and implications for interventions, are discussed.

Keywords Review · Gene-environment interactions · Externalizing behaviors · Postnatal family adversity . Theoretical mechanisms

\section{Introduction}

Caspi et al. (2002) found the adverse effect of maltreatment on antisocial behaviors to be moderated by a functional polymorphism in the monoamine oxidase $\mathrm{A}$ (MAOA) gene. Following this exciting discovery, a fast paced research field emerged focusing on candidate gene by environment interactions $(\mathrm{cG} \times \mathrm{E})$. Since then the original findings have been replicated, as well as extended to interactions between a broad variety of candidate genes and environmental risk factors in predicting different forms of externalizing behaviors. These findings have taught us much about the interplay of genes and environment in the development of externalizing behaviors. However, the literature has also raised some criticism and important growing pains of the field are difficulties with replication and contradictory findings, which complicates creating a consistent picture (e.g., Dick et al. 2015; Duncan and Keller 2011; Jaffee et al. 2013; Rutter 2012). Multiple meta-analyses on $\mathrm{cG} \times \mathrm{E}$ in externalizing behaviors have already been published, but these have mostly focused on the MAOA gene (Byrd and Manuck 2014; Kim-Cohen et al. 
2006; Taylor and Kim-Cohen 2007). A complete overview of $\mathrm{cG} \times \mathrm{E}$ in externalizing behaviors is missing (for a general overview of $\mathrm{cG} \times \mathrm{E}$ in psychopathology see Duncan and Keller 2011). In part one of this paper, we therefore try to create a comprehensive overview and integration of the findings so far, by reviewing 53 published $\mathrm{cG} \times \mathrm{E}$ studies including interactions between the six most studied candidate genes (i.e., the monoamine oxidase A (MAOA), the dopamine receptors D4 (DRD4) and D2 (DRD2), the dopamine transporter 1 (DAT1), the $5^{\prime}$ serotonin transporter linked polymorphic region (5HTTLPR), and the catechol- $O$-methyltransferase (COMT)) and postnatal family adversity in externalizing behaviors, such as aggression, and conduct disorder.

Another issue concerning $\mathrm{cG} \times \mathrm{E}$ is that there is a lack of insight into biopsychosocial mechanisms that underlie such interactions (see also Battaglia 2012; Dodge 2009; Salvatore and Dick 2015). At present, looking at $\mathrm{cG} \times \mathrm{E}$ findings is like looking at a "black box," in that we are only aware of what goes in and what comes out. However, insights into how these $\mathrm{G} \times \mathrm{E}$ interactions work (i.e., "how genes get outside the skin," Reiss and Leve 2007) is of great empirical and clinical importance. From an empirical perspective, it might help us form specific theory-based hypotheses that can specify our research strategies. From a clinical perspective, information on working mechanisms will increase our insight into which proximal variables (i.e., neurobiological and psychological characteristics, rather than genotypes) moderate the effects of family adversity on specific externalizing behaviors. Also, it can increase our knowledge of differential (biological) pathways leading to externalizing problems. This knowledge could in turn be used to tailor interventions by indicating the needed clinical focus, increasing their effectiveness (Matthys et al. 2012). In part two of this paper, we therefore put forward three possible, and complementary, theoretical mechanisms underlying $\mathrm{G} \times \mathrm{E}$. These proposed mechanisms are based on extant literature about genetic, neurobiological, psychological, and environmental factors within externalizing behaviors.

\section{Genes, Postnatal Family Adversity, and Externalizing Behaviors: A Systematic Review of $\mathbf{G} \times \mathbf{E}$ Findings}

\section{Methods}

This systematic review considers candidate genes that are studied most extensively in the context of externalizing behaviors, namely polymorphisms regulating the activity of the neurotransmitters dopamine and serotonin, which are associated with various aspects of human behavior: the
MAOA, DRD4, DRD2, DAT1, 5-HTTLPR, and COMT val/ met. We conducted a literature search for studies on interactions between these polymorphisms and indices of postnatal family adversity in predicting externalizing behaviors (i.e., aggression, behavioral problems, antisocial behavior, Oppositional Defiant Disorder (ODD), Conduct Disorder (CD), delinquency, psychopathy). Our review focus is on externalizing behavior, because these behaviors are relatively common in childhood, and a childhood onset of such problem behavior is known to be a strong predictor of psychopathological outcomes later in life (e.g., Jokela et al. 2009; Von Stumm et al. 2011). However, externalizing behavior is a very heterogeneous behavioral cluster, which has different etiologies in different children and across symptoms (e.g., Frick 2012). Specifically, Attention Deficit Hyperactivity Disorder (ADHD) might be a distinct disorder in symptomatology (i.e., attention deficits) and etiology (e.g., stronger heritability than other externalizing disorders, Burt 2009). Therefore, to narrow the scope of our review, we did not include studies that focused specifically and solely on ADHD as an outcome variable, but did include studies that included ADHD as one of multiple (comorbid) outcome measures. Family adversity (i.e., family and parental characteristics that are associated with increased risks of child maladjustment) is one of the most well-studied and documented contributors to child externalizing behaviors, as well as an important target for interventions aimed at reducing externalizing behaviors (for an overview see Tolan et al. 2013).

We searched digital databases (i.e., PsycINFO, PubMed, Google Scholar) for peer-reviewed papers between January 2002 and May 2015 using the terms: adverse family environment, SES, parent* (the asterisk indicates that the search contained that word base), maltreatment, and psychosocial (environmental factors); $\mathrm{G} \times \mathrm{E}$, gene-environment, $D R D 4$, DRD2, MAOA, 5-HTT*, DAT1, and COMT (genetic factors); and all combinations of these factor terms. Also, we searched reference lists of published studies, meta-analyses, and review articles, and contacted authors for possible additional studies. The last search took place on May 1, 2015.

After our original search, 102 studies were selected, of which 49 were excluded because they did not report on externalizing behaviors as defined above as an outcome (e.g., but on ADHD or on externalizing behavior-related constructs such as behavioral disinhibition); did not address postnatal family adversity (e.g., but prenatal adversity such as maternal smoking, or risk factors outside the family such as neighborhood); reported exclusively on beneficial family environments, or enrichment of this environment (e.g., maternal warmth or intervention studies: for an overview of RCT's testing cG $\times \mathrm{E}$ see Van IJzendoorn and Bakermans-Kranenburg 2015); or reported on interactions that were based on cumulative or polygenic effects only. We 
did include studies that addressed multiple genes, and findings for all genes were reviewed separately. We also included studies that addressed genetic differential susceptibility rather than genetic risk (i.e., "for better and for worse" interactions; Belsky 2005). It has been hypothesized that the same genetic markers associated with children being relatively vulnerable, and in consequence do worse under environmental adversity (e.g., develop externalizing behaviors), might also be associated with them also being relatively susceptible, and in consequence do better under environmental enrichment (e.g., develop prosocial behavior), compared to children without this marker (Belsky et al. 2007). Moreover, under some supportive environmental circumstances these same markers might even point to a genetic advantageous for children's development (i.e., vantage sensitivity, Pluess and Belsky 2013). However, because most studies test the cumulative aversive effects of genotype and environment (i.e., dual risk), rather than differential susceptibility or vantage sensitivity, we solely reviewed findings involving environmental adversity (i.e., the "for worse" part). For example, when a study assessed both high (i.e., beneficial) and low (i.e., aversive) responsive maternal caregiving (Nikitopoulos et al. 2014), we only reviewed $\mathrm{G} \times \mathrm{E}$ involving low responsive maternal caregiving. After inclusion, we contacted corresponding authors of the studies in order for them to check the included information, and ask them for possible other studies to include. A limitation of our overview is that we were unable to fully control for a possible "file drawer effect." Unpublished studies may on average report different results from published studies.

\section{Results}

Our review includes 53 studies. We will discuss the results of the review by polymorphism, starting with a short introduction of the polymorphism in question, stating the number of included studies on this polymorphism and using a "vote counting" procedure for describing the findings (i.e., clustering results in the same direction). Integration of the findings will follow after each results paragraph and in the discussion of part 1. A list of included studies and how they were coded is provided in Table 1.

\section{$M A O A$}

The MAOA gene codes for the monoamine oxidase A enzyme, which is involved in the degradation of dietary amines and neurotransmitters, such as serotonin and dopamine. The gene is located on the X-chromosome, this means that women have two alleles and men have only one. The MAOA polymorphism is a Variable Number
Tandem Repeat (i.e., VNTR polymorphism) in the promoter region of the gene starting 43,515,409 basepairs from the end of the chromosome (pter), comprising a 30-basepair repeat sequence present in 2, 2.5, 3, 3.5, 4, 5, or 6 copies (Sabol et al. 1998). The 2 and 3-repeats are indicated as "low-activity variant" and the 3.5 and 4-repeat sequences as "high-activity variant." Although distribution varies among different populations, the 3 and 4-repeats are usually the most prevalent. To date, there is no consensus on the activity level of the less-prevalent 2.5 and 5-repeat (see Deckert et al. 1999), and the 6-repeat has not been functionally characterized. The high-activity alleles code for higher transcription of monoamine oxidase A, resulting in an increased degradation-and thus decreased concentrations-of dopamine and serotonin in the brain (Denney et al. 1999; Sabol et al. 1998). Dopamine is involved in, among others, motivation, motor control, and cognition (Missale et al. 1998) and serotonin in memory, learning, and mood (Pezawas et al. 2005). A decreased concentration of dopamine and serotonin is linked to impulsivity, antisocial behavior, and alcoholism (e.g., Eme 2013; Schmidt et al. 2000). Furthermore, the MAOA polymorphism has also been directly related to antisocial behavior (for a metaanalysis, see Ficks and Waldman 2014). See for an overview of dopamine-related $\mathrm{cG} \times \mathrm{E}$ Bakermans-Kranenburg and Van IJzendoorn (2011).

We found 31 studies including the MAOA polymorphism, family adversity, and externalizing behaviors (Table 1). The original Caspi et al. (2002) finding that the effect of family adversity on externalizing behaviors is larger among low-activity allele carriers has been replicated 16 times. We found four studies that reported this effect to be larger among high-activity allele carriers, and we found ten null findings (i.e., no interaction effect). It is important to note, however, that studies replicating the original interaction differed in how they operationalized the low-activity allele-sometimes as 3; as 2 and 3; as 2.5 and 3; or as 2, 3, and 5-repeat sequences. A recent metaanalysis of Byrd and Manuck (2014) shows a moderately consistent interaction between the low-activity allele and maltreatment in predicting conduct problems in males. For other environmental adversities, however, the interaction was found to be less consistent. This might indicate that specific polymorphisms interact with specific environmental factors, in predicting specific externalizing behavior. For example, the MAOA might interact with harsh parenting and maltreatment (e.g., Weder et al. 2009), through a specific mechanism of vulnerability predicting antisocial and aggressive behavior, but might not necessarily interact with other environmental factors such as poverty (e.g., Hart and Marmorstein 2009), and might not necessarily predict other forms of externalizing behavior (e.g., psychopathic traits, Sadeh et al. 2013). 


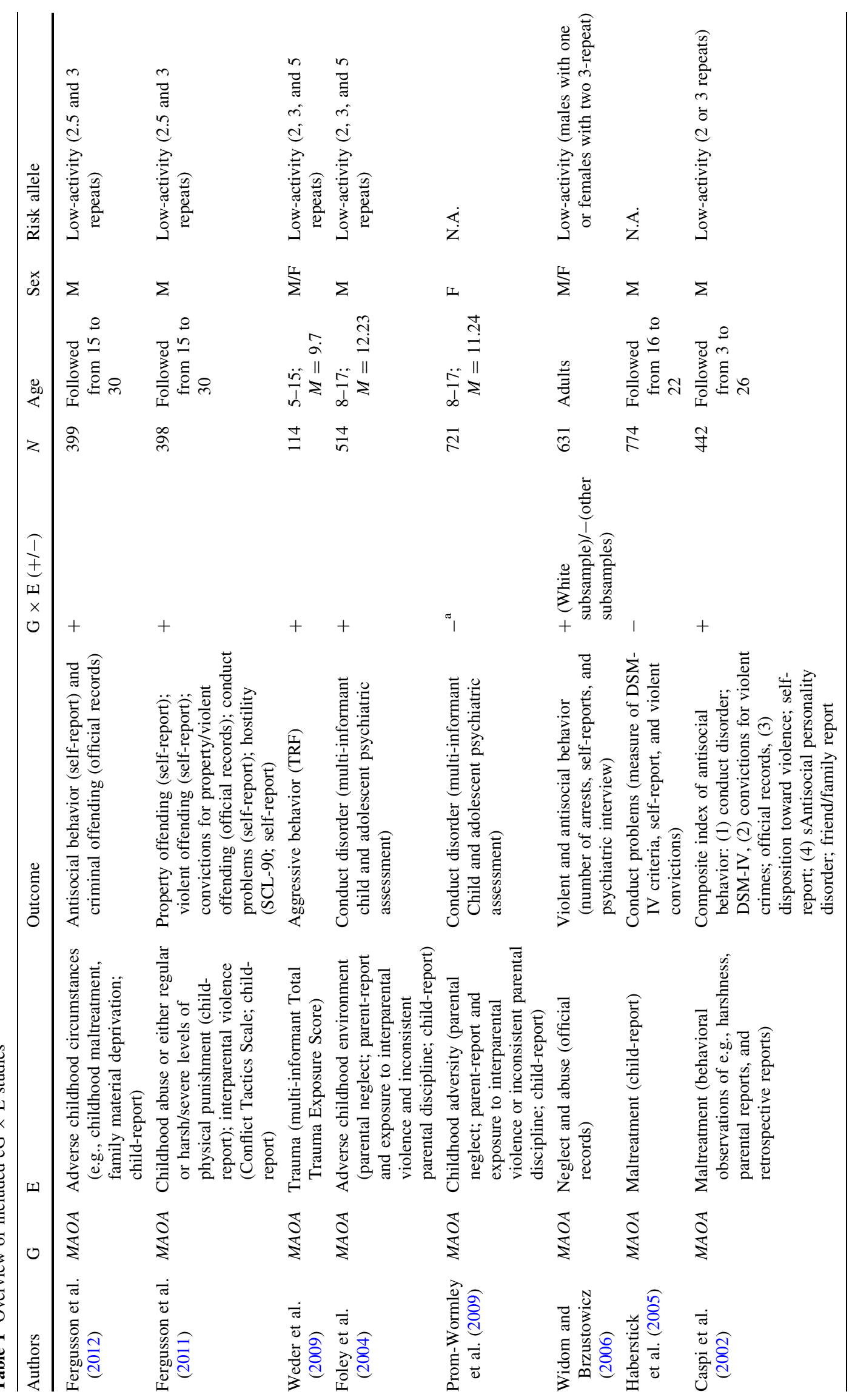




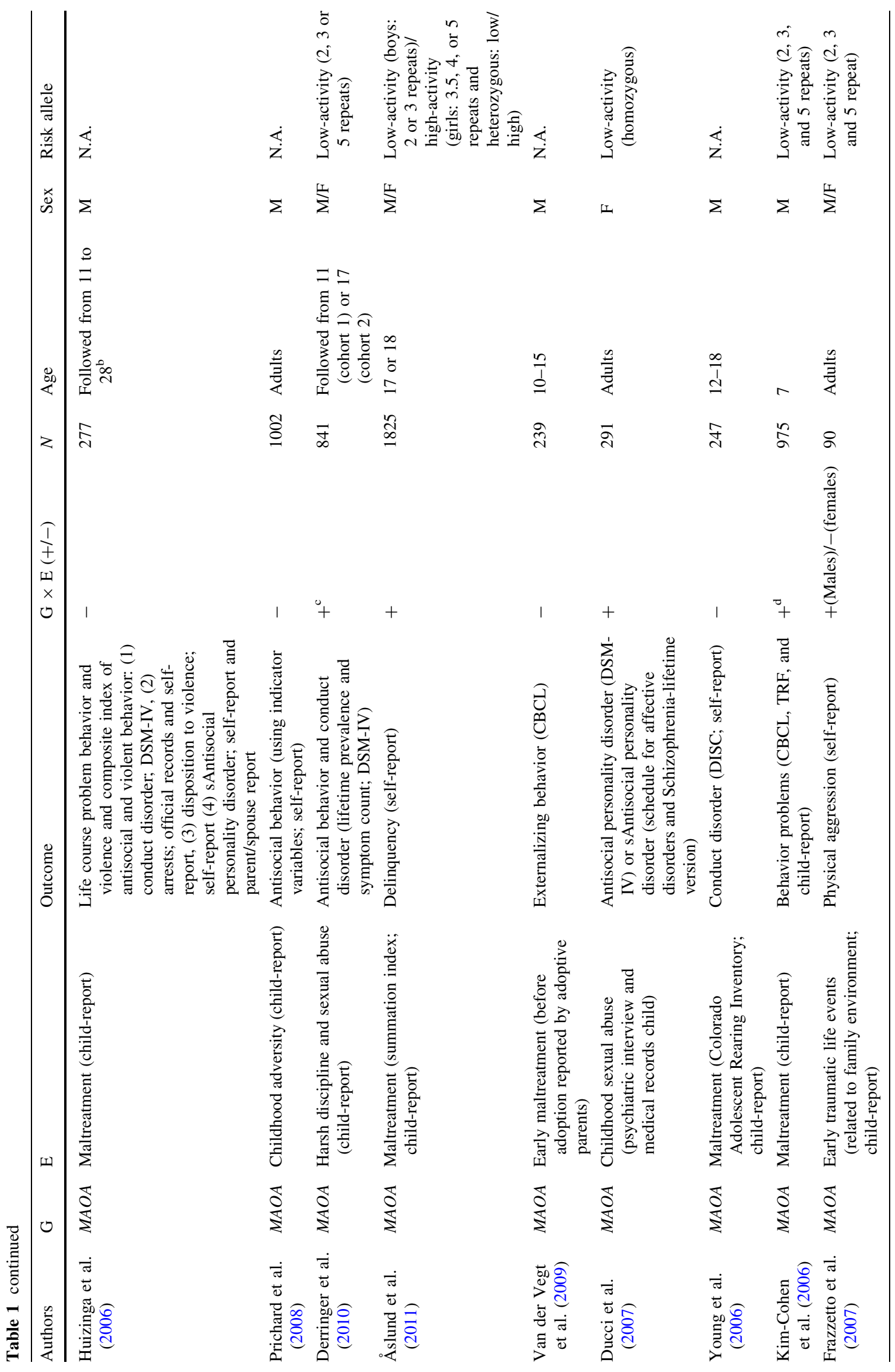




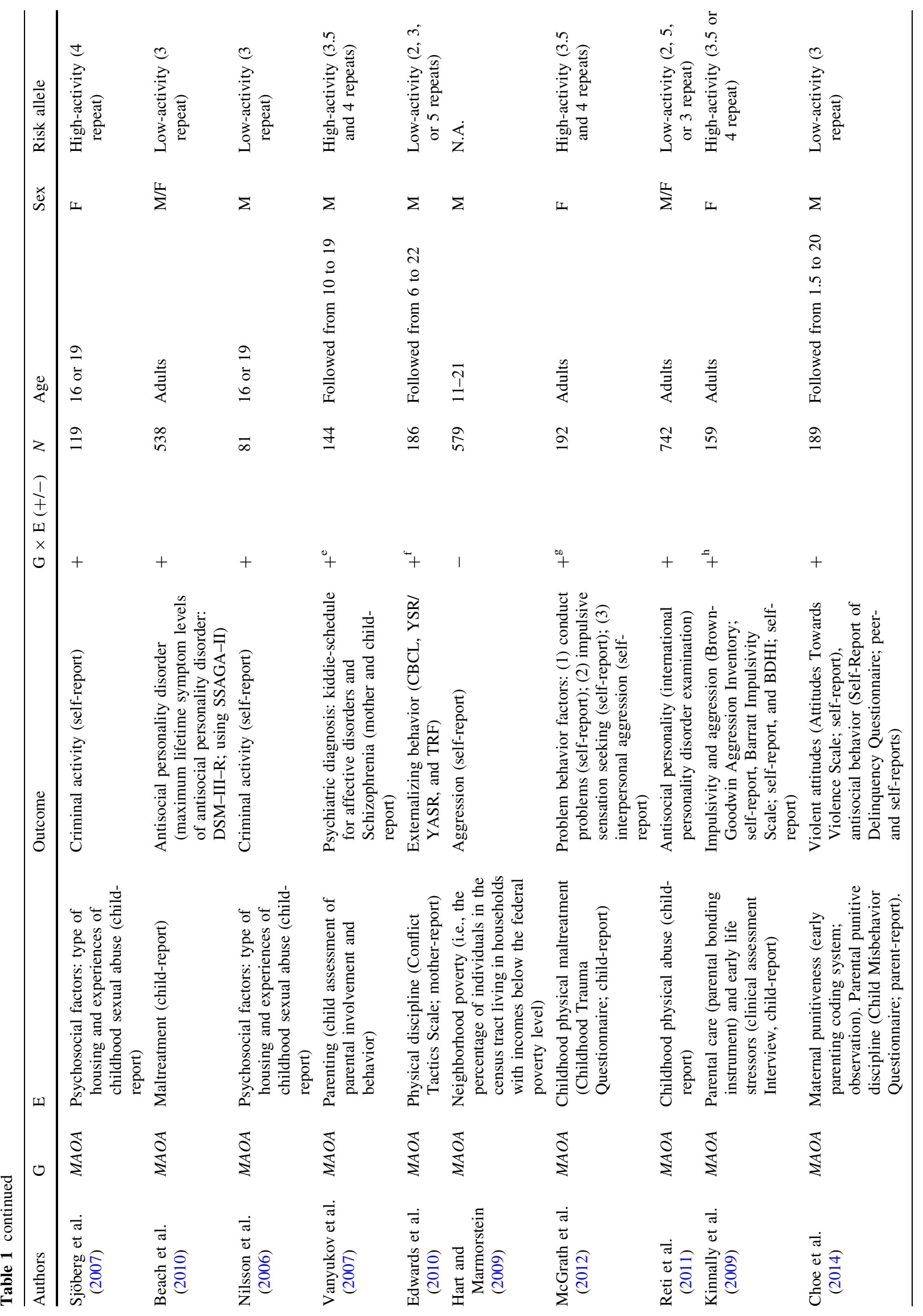




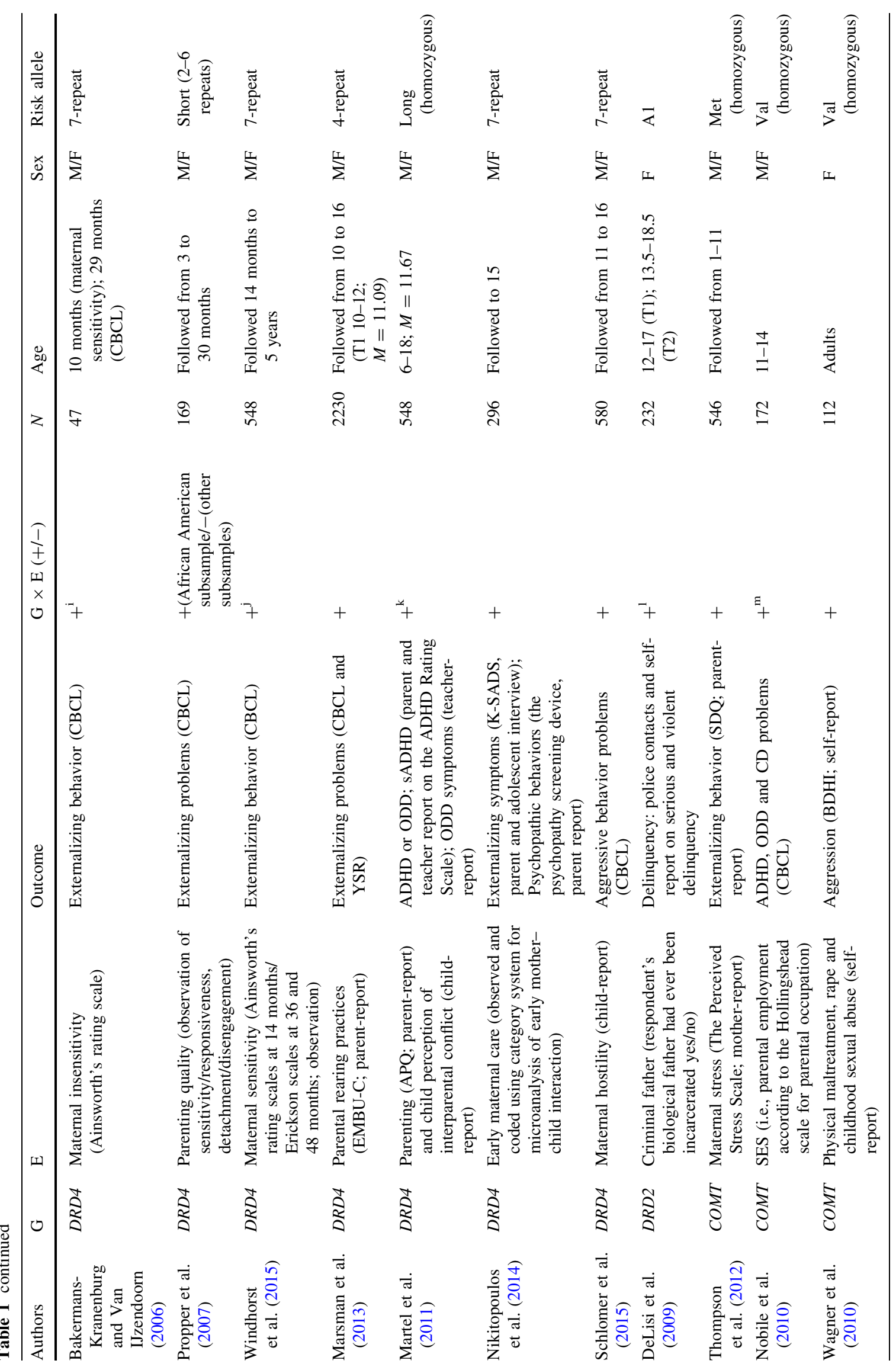




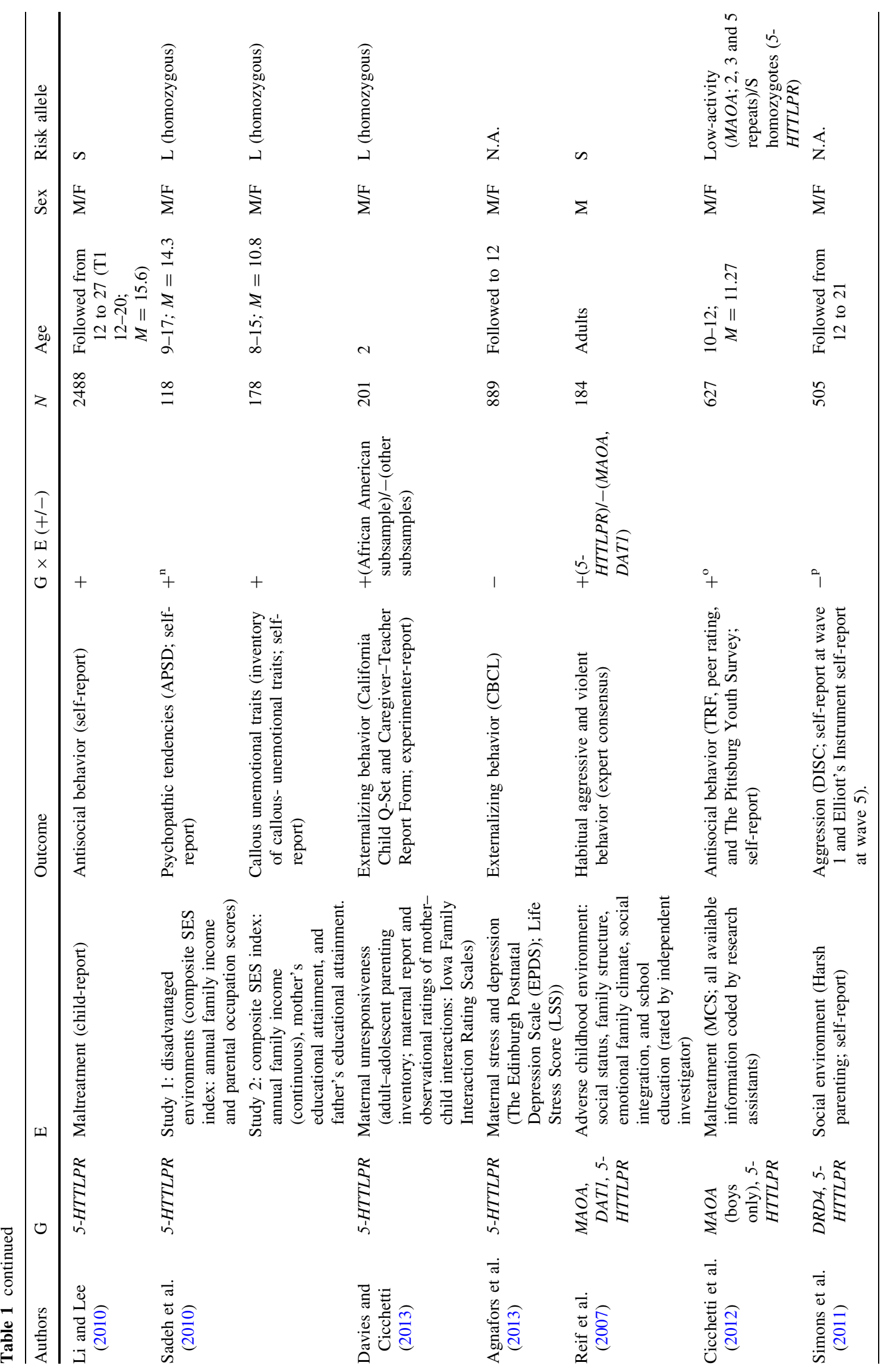




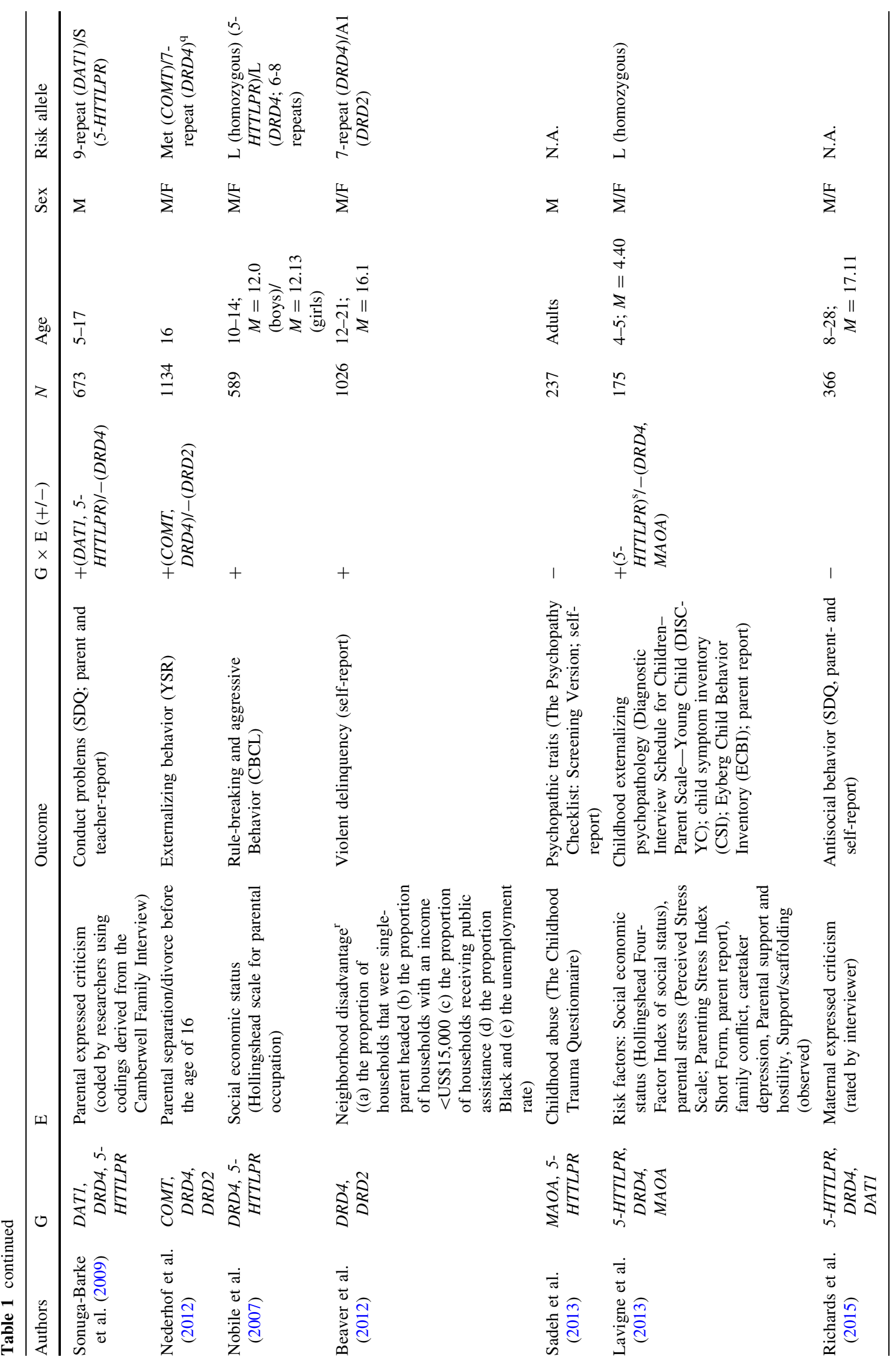




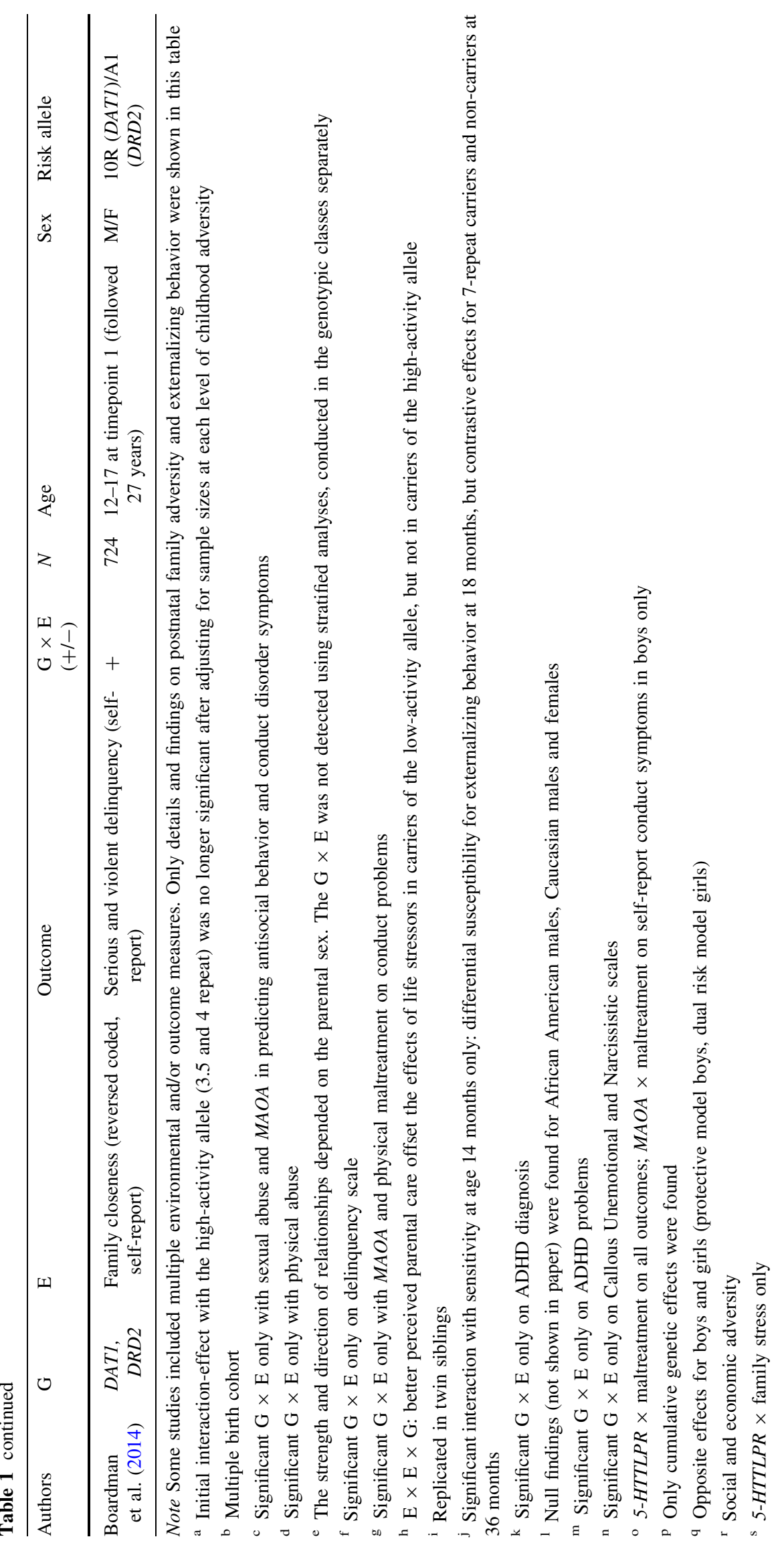


Opposed to male populations, in female populations there was a significant interaction found between environmental adversity and the high-activity allele in predicting externalizing behaviors. We know little about how these sex differences might be explained, although the literature does suggests different possibilities. First, the differences might be partly due to the fact that the MAOA is an X-linked polymorphism. The role of MAOA genotype on MAOA expression might be more unpredictable for women than for men (e.g., Carrel and Willard 2005; Pinsonneault et al. 2006). Second, MAOA expression might be affected by sex hormones such as testosterone (Ou et al. 2006; Sjöberg et al. 2007). High testosterone levels may lead to lower transcription of MAOA and lower MAOA levels. Because of higher testosterone levels, men might show lower levels of $M A O A$ in general, which in turn might have larger effects on dopamine availability and in turn behavior, compared to women. This explanation might be specifically interesting for studies addressing adolescence, when testosterone levels are particularly high. Third, the effect or prevalence of the environmental risk factor, and/ or the mechanism underlying the interaction between environmental risk and MAOA genotype, might be different for boys than for girls (Beach et al. 2010). For example, within the broad measure of childhood maltreatment, neglect might be a particularly important risk factor for externalizing behavior in boys, while sexual abuse is more important for girls.

\section{DRD4}

The DRD4 gene codes for the D4 subtype of dopamine receptors (i.e., dopamine binding sites) in the brain. The DRD4 polymorphism is a VNTR in exon 3 of the gene starting 637,293 basepairs from pter, comprising a 48 nucleotide repeat sequence ranging from 2 to 11 copies (Van Tol et al. 1992). The common 2-5 repeats are indicated as "short" and 6-10 repeats as "long" variants of the polymorphism. The long-allele is associated with significantly reduced amounts of D4 receptors in the brain (Asghari et al. 1995). Specifically, the relatively common 7-repeat allele is related to a blunted dopamine response (Schoots and Van Tol 2003), which has been related to a reduced reward processing (for a review see Comings and Blum 2000). Lower amounts of dopamine receptors have been consistently found in people suffering from substance abuse (Li et al. 1997; Volkow et al. 1997). Polymorphisms coding for lower amounts of dopamine receptors seem to moderate the effects of environmental adversities on the development of different forms of psychopathology (for a meta-analyses see Bakermans-Kranenburg and Van IJzendoorn 2011).
We found 14 studies including the DRD4 polymorphism, family adversity, and externalizing behaviors (Table 1). Nine studies found the effect of family adversity on externalizing behaviors to be larger among carriers of the long-allele, of which seven studies found this specifically for the 7-repeat allele. Two studies found this effect to be larger among carriers of the short-allele, of which one study found this specifically among 4-repeat allele carriers and one study among carriers of the short-allele operationalized as 2-6-repeats. Three null findings have been published. Some of these inconsistencies between findings might be due to differences in sample composition between studies, specifically differences in sample age. The mean sample age of studies on the DRD4 varies between 10 months at the first time point of a longitudinal study and around 16.5 years at the last measurement point of a longitudinal study. It might be that certain $\mathrm{cG} \times \mathrm{E}$ are age specific: There might be critical (i.e., restricted developmental periods in which influences of a particular $\mathrm{G} \times \mathrm{E}$ occurs) and sensitive (i.e., developmental periods in which influences of a particular $\mathrm{G} \times \mathrm{E}$ are more likely to occur) periods (see for a critical discussion and examples, Reiss et al. 2013). For example, Windhorst et al. (2015) found the DRD4 genotype to moderate the relation between maternal insensitivity at 14 months and externalizing behavior at 18 months, but not at 48 months (i.e., at the ages of 48 months and up maternal insensitivity predicted child externalizing behavior, independent of DRD4 genotype). Moreover, for different age groups, different assessment tools exist. Therefore, such age differences might bring about differences in the measurements used to assess the environment and/or behavioral outcomes.

Sex differences have also been reported. Opposite effects of the DRD4 polymorphism have been found for boys and girls (i.e., protective model for boys and dual risk model for girls; Nederhof et al. 2012). It might very well be that the mechanisms underlying such interactions are different for boys and girls. Another explanation might be that some $\mathrm{cG} \times \mathrm{E}$ are explained by confounding effects of covariates such as gender, ethnicity, or social economic status (see, e.g., Keller 2014). For example, Dmitrieva et al. (2011) found that the gender-specific direct effects of the DRD4 on externalizing behavior were explained by differences in exposure to family adversity (i.e., poor parental monitoring and exposure to violence). Some cG $\times$ E regarding the $D R D 4$ might therefore be explained by a gender-by-adversity or a gender-by- $D R D 4$ interaction. In the case of monitoring, the literature suggests that parental monitoring is a stronger predictor of externalizing behavior in boys, than in girls (Jacobson and Crockett 2000), and that boys receive less parental monitoring than girls (e.g., Webb et al. 2002), specifically when they carry the DRD4 7-repeat allele (Dmitrieva et al. 2011). 


\section{DRD2}

The DRD2 gene codes for the D2 subtype of the dopamine receptors. The Taq1A DRD2 polymorphism is a single nucleotide polymorphism (SNP) (rs 1800497) of the gene, resulting in a cytosine $(\mathrm{C})$ to thymine $(\mathrm{T})$ substitution. The less frequent A1-allele $(\mathrm{T})$ is associated with significantly reduced amount of D2 receptors in the brain compared to the A2-allele (C) (Noble et al. 1991), which might result in a blunting of dopamine signals. The A1-allele is associated with impulsivity (Eisenberg et al. 2007). However, more recently, this polymorphism has been more precisely located within the coding region of a neighboring gene (10 kb downstream the DRD2 gene), named ANKK1. $A N K K 1$ activity may provide an alternative explanation for previously described associations between the DRD2 and neuropsychiatric disorders (Neville et al. 2004).

We found four studies including the DRD2 polymorphism, family adversity, and externalizing behaviors (Table 1). One study reported a null finding. Three studies found a significant interaction effect, in which the effects of family adversity were larger among carriers of the A1allele. The three significant findings all related to interactions between the DRD2 and family dysfunctioning on adolescent delinquency (Beaver et al. 2012; Boardman et al. 2014; DeLisi et al. 2009). One study that did not find a significant interaction focused on the interaction between the $D R D 2$ and early parental separation on externalizing behavior (i.e., YSR, Nederhof et al. 2012). The different findings between these studies might therefore be explained by differences in the conceptualization of family adversity and/or externalizing behavior outcome. Children's DRD2 genotype might not affect the relation between parental separation-which might not necessarily correlate with the experience of family dysfunctioningand externalizing behavior, whereas it does affect the relation between family adversity measures, such as the experience of having an incarcerated father or a lack of family closeness, and delinquency. Alternatively, the DRD2 might interact with family adversity in predicting adolescent delinquency, but not in predicting other or broader forms of externalizing behavior.

\section{DATI}

The DAT1 gene (SLC6A3) regulates the uptake of dopamine by influencing the quantity of dopamine available in the synapses in the brain (i.e., striatum, prefrontal cortex, and hypothalamus). The DAT1 polymorphism is a VNTR on the $3^{\prime}$-untranslated region of the gene starting $1,392,905$ basepairs from pter, comprising a 480 basepair repeat sequence varying between 3 and 11 copies. The 9 and 10 -repeat are the most common variants (VanNess et al.
2005). Lower expression of the DAT1 is related to lower dopamine availability in the synapses of the brain. There are conflicting findings regarding the expression levels of the 9-repeat and 10-repeat alleles (e.g., Heinz et al. 2000; Van Dyck et al. 2005). The 9-repeat is (population specifically) associated with addiction (Bhaskar et al. 2012), whereas the 10-repeat allele is associated with impulsivity (for a meta-analysis, see Yang et al. 2007).

We found four studies including the DAT1 polymorphism, family adversity, and externalizing behaviors: Two studies reported a null finding and two studies found a significant interaction (Table 1). These latter two studies, however, both reported larger effects of family adversity among carriers of different DATI variants (i.e., the 10-repeat allele or the 9-repeat allele). Again, an explanation might be found in the large differences in family adversity measures, which ranges from parental expressed criticism, and global institutional deprivation, to family closeness. Studies might be incomparable because they simply test relations between different constructs. It is questionable if similar outcomes are to be expected between studies testing interactions with such different environmental adversity and outcome measures.

\section{COMT}

The COMT gene codes for the catechol-O-methyltransferase enzyme, which breaks down catecholamines including dopamine, thus clearing them from the synapse. The COMT polymorphism is a SNP (rs 4680) resulting in a valine (i.e., Val) to methionine (i.e., Met) mutation. The Val-allele is related to higher activity than the Met-allele-with differences up to $400 \%$-leading to lower synaptic dopamine levels (e.g., Chen et al. 2004; Lotta et al. 1995). This polymorphism is related to individual differences in emotional processing (stronger activation of the prefrontal cortex in Met-allele carriers) and cognitive processing (reduced prefrontal cortex efficiency for Val-carriers) (for a meta-analysis, see Mier et al. 2009). A meta-analysis showed no direct associations between the COMT polymorphism and externalizing psychopathology (Munafò et al. 2005), but indications were found that heterozygosity serves as a protective factor for psychopathology (Costas et al. 2011).

We found four studies including the COMT polymorphism, family adversity, and externalizing behaviors (Table 1). Two studies found the effect of family adversity to be larger among carriers of the Met-allele and two studies among carriers of the Val-allele. For example, Wagner et al. (2010) showed that women who carried the Val-allele-and had been maltreated during their childhood-manifested more hostile antisocial behavior compared to non-carriers. In contrast, Thompson et al. (2012) found the effects of maternal stress on externalizing 
behavior to be larger for children homozygous for the Metallele than for children with the Val-allele. In the case of the COMT polymorphism, this seemingly contradiction might be explained by a cognitive/emotional trade-off (i.e., the warrior-worrier hypothesis, Goldman et al. 2005), in which the Val-allele is associated with an advantage in emotional processing and the Met-allele in cognitive processing (see Mier et al. 2009). The Met-allele (i.e., the worrier) has been associated with an advantage for prefrontal cortex-and related cognitive-functioning. However, at the same time this allele might form a genetic predisposition for heightened emotional arousal and affective responses, and lower emotional control, which might contribute to emotional dysregulation, an irritable mood and externalizing behavior reported in Met/Met individuals (e.g., negative mood, irritability and affective disorders) (e.g., Drabant et al. 2006; Williams et al. 2010; Thompson et al. 2012). The Val-allele (i.e., the warrior) has been associated with better stress and anxiety resistance, but lower executive functions (Wishart et al. 2011) and cognitive control (Kilford et al. 2015), which might contribute to deficits in response inhibition, and substance dependence in Val-carriers (e.g., Nobile et al. 2010; Gratacòs et al. 2007). The two different alleles might therefore both function as genetic risk and/or advantage under different environmental adversity.

\section{5-HTTLPR}

The 5-HTT gene (SLC6A4) codes for serotonin transporters, which are involved in the active clearance and termination of synaptic serotonin. The 5-HTT gene linked polymorphic region, or 5-HTTLPR, is a polymorphism in the promoter region of the gene. The 5-HTTLPR starts $28,521,337$ basepairs from pter and consists of a 20-23 basepair repeat sequence. The two most common variants of the polymorphism are typically defined as a "short-allele" (i.e., S-allele, low expressing) comprising 14 copies and a "long-allele" (i.e., L-allele, high expressing) comprising 16 copies. The S-allele has been related to significantly lower 5-HTT mRNA and protein, lower uptake and consequently higher and less stable concentrations of serotonin in the synaptic cleft, compared to the L-allele (e.g., Greenberg et al. 1999; Lesch et al. 1996, but for contrasting findings see Naylor et al. 1998). Serotonin is indicated as an important modulator of neural circuitry that controls a wide range of behavioral and physiological processes including mood (e.g., Pezawas et al. 2005). The 5 -HTTLPR polymorphism is intensely studied in association with internalizing problems (e.g., Uher and McGuffin 2007), but has also been related to other forms of child and adolescent psychopathology (see Van IJzendoorn et al. 2012).
We found 12 studies including the 5-HTTLPR polymorphism, family adversity, and externalizing behaviors (Table 1). Four studies found the effect of family adversity to be larger among carriers of the S-allele. In contrast, four studies found this to be larger among carriers of the L-allele. These findings might indicate that both the 5-HTTLPR $\mathrm{S}$-allele and the L-allele might contribute to externalizing behavior after exposure to family adversity, through different pathways. The S-allele might be related to increased neural activity (e.g., Murphy et al. 2013), affective and physiological reactivity (e.g., Gyurak et al. 2013, but for contrasting findings see Weeland et al. 2015), and lower levels of positive affect (e.g., Hankin et al. 2011), after exposure to negative emotions. This heightened emotional reactivity might form a risk for irritability and reactive aggression when exposed to negative emotions (e.g., Cicchetti et al. 2012), whereas the L-allele might be related to emotional hyporeactivity and punishment insensitivity (for a review see Glenn 2011), and might therefore be a risk for proactive and predatory behavior when socialization is mainly based on punishment (e.g., Sadeh et al. 2010).

Four studies reported a null finding. However, this number might be misleading since it has been show that specifically the literature on the 5-HTTLPR in externalizing behavior might suffer from a publication bias in favor of statistically significant findings (Ficks and Waldman 2014). Also, ethnic differences have been found. Specifically, Davies and Cicchetti (2013) found that African American 2-year-olds-but not 2-year-olds from other ethnic subgroups-homozygous for the L-allele were more susceptible to maternal unresponsiveness in developing externalizing behaviors, compared to carriers of the S-allele. The L-allele has been shown to be more common among African Americans, compared to other ethnic groups (Enoch et al. 2006). Such differences in allele frequency might be important for several reasons. First, it might bring about differences in group sizes regarding the relevant genotypes (e.g., a relative larger group of L-carriers in African American samples than equally large samples of other ethnicity), and therefore power, between studies with different sample compositions. Second, due to possible gene-environment or gene-behavior correlations, it might cause differences between study samples in the prevalence of the specific environmental risk factor and/or outcome behavior.

\section{Discussion}

The initial stage of the $\mathrm{cG} \times \mathrm{E}$ research field has yielded an interesting set of results, detecting many interaction effects between genetic polymorphisms and family adversity on externalizing behaviors. Our review of this literature shows a large set of studies that feature mixed results (see Table 1). To illustrate, for the 5-HTTLPR VNTR 
polymorphism, null findings (4 out of 12) as well as interactions with both the S-allele (4 out of 12) and L-allele (4 out of 12) as "risk allele" have been reported. Furthermore, heterogeneity of results might be underestimated due to a publication bias in this field favoring statistically significant findings over nonsignificant findings (see Duncan and Keller 2011; Ficks and Waldman 2014). Based on this, one might conclude that $\mathrm{cG} \times \mathrm{E}$ has failed to deliver conclusive evidence for specific $\mathrm{cG} \times \mathrm{E}$. However, our review also makes clear that-even though we specified our search terms by means of a specific environmental factor and outcome-most studies have large methodological differences, which makes it difficult to make cross-study comparisons of findings. Findings on $\mathrm{cG} \times \mathrm{E}$ concerning the MAOA polymorphism seem to be an exception, showing a relatively consistent pattern. This might be partly explained by the fact that studies on this polymorphism have been using-more so than studies on other polymorphisms - more similar measures for family adversity (i.e., abuse and maltreatment) and outcome behavior (i.e., antisocial behaviors and conduct disorder).

The methodological differences between studies largely fall under three categories, namely sample size and composition, conceptualization, and power. These differences have been addressed extensively before (see for a critical review Dick et al. 2015; Jaffee et al. 2013) and therefore will only be discussed briefly. First, our table shows that both sample size (i.e., the $N$ ranged from 47 to 2488) and composition-in terms of sex, ethnicity/geography, and age-vary strongly between studies. This is important, given that differential genetic effects should be expected by sex (e.g., Nordquist and Oreland 2010) and ethnicity or geography, the latter based on population stratification (e.g., Manica et al. 2005; Enoch et al. 2006). Some of the inconsistencies between findings might be explained by ethnic differences in allele frequency (e.g., Enoch et al. 2006), sex and/or ethnic differences in the prevalence of specific externalizing behaviors and environmental risk factors (e.g., Miner and Clarke-Stewart 2008), or differences in the mechanisms underlying externalizing behavior (see Deater-Deckard and Dodge 1997). Therefore, specific $\mathrm{cG} \times \mathrm{E}$ found in one population might not necessarily be replicated in another. Age also plays an important role, given that across age groups different tools are being used to assess the environment and behavioral outcomes. Moreover, different predictors play a key role across different developmental stages (Moffitt et al. 2006). Thus, again a specific $\mathrm{cG} \times \mathrm{E}$ found within one developmental period might not necessarily be replicated in another. This is especially relevant in light of the fact that previous longitudinal $\mathrm{cG} \times \mathrm{E}$ studies have targeted samples within a broad range of different developmental periods. More specifically, it might be that there are sensitive periods for specific cG $\times$ E (Belsky and Pluess 2013; Reiss et al. 2013).
An example of such "timing effects" for $\mathrm{cG} \times \mathrm{E}$ involving the MAOA can be found in Choe et al. (2014) and involving the DRD4 in Windhorst et al. (2015). Moreover, it has also been found that the effects of a polymorphism on brain function might be age dependent (e.g., Meyer et al. 2014). Future research should therefore not only focus on if and how specific $\mathrm{cG} \times \mathrm{E}$ occurs, but also on the timing of specific $\mathrm{cG} \times \mathrm{E}$ (i.e., when it occurs).

Second, our review shows that studies on $\mathrm{cG} \times \mathrm{E}$ are characterized by a large diversity in the conceptualization of, and type of measures used to assess, both family adversity and externalizing behaviors (e.g., present vs. retrospective; self-reported vs. observed behavior). Moreover, disparate concepts are sometimes described using the same terminology. To illustrate, antisocial behavior has been assessed with the number of arrests, as well as the amount of DSM-related symptoms. This issue is not specific to literature on $\mathrm{cG} \times \mathrm{E}$. However, although it is important that original findings are extended by broadening the scope of predictors, outcomes, and populations, these large differences between studies makes it difficult to make cross-study comparisons. This is important since new hypotheses on $\mathrm{G} \times \mathrm{E}$ are often based on previous findings, regardless of these differences. This approach might not be specific enough, leading to hypotheses based on inadequate literature or theory. Also, this diversity raises a fundamental question within the field of $\mathrm{G} \times \mathrm{E}$ : Do we expect a polymorphism to be related to individual differences in susceptibility to the environment in general, or to individual differences in susceptibility to specific environmental factors through specific risk mechanisms? And also, do $\mathrm{G} \times \mathrm{E}$ underlie psychopathology in general or do they underlie specific psychopathological outcomes? The inconsistent findings between different studies seem to suggest specific rather than general interactions between genes and environment. Moreover, which allele of a specific polymorphism should be considered the "risk" allele for externalizing behavior might be dependent on the specific study population, adversity measure, and outcome measures used. We gave specific examples of how both alleles of the COMT and 5-HTTLPR polymorphisms, through different mechanisms, might form a risk factor for different externalizing behaviors. Moreover, some alleles might even form a "risk" factor for specific externalizing behavior when exposed to certain environmental adversity, while at the same time being "advantageous" when exposed to other environmental factors (e.g., the emotional/cognitive tradeoff in case of the COMT). Third, the described differences in sample size and conceptualization bring about differences in statistical power (see Caspi et al. 2010; Duncan and Keller 2011), affecting the a priori likelihood that studies will come up with significant and replicable $\mathrm{cG} \times \mathrm{E}$ findings (see also Simmons et al. 2011). 
Given these large methodological differences between the studies, different findings are simply to be expected and do not necessarily illustrate that findings are contradictory. One way to help build a more consistent literature base, to establish better comparable findings, and to consequently draw more solid conclusions about the role of $\mathrm{cG} \times \mathrm{E}$ in externalizing behaviors, might be through specifying a priori hypotheses: How do specific family adversity factors interact with specific genetic polymorphisms, in predicting specific behavior in specific samples, and in turn by stating our research strategies accordingly. This approach will also reduce the chance of spurious findings due to chance capitalization (Type I errors) and will allow scholars to conduct a priori power analyses, reducing chances of false negatives (Type II errors). To be able to state adequate hypotheses however, we need to move away from the exploratory phase and form a more biologically informed understanding of these interactions. Insight into mechanisms underlying $\mathrm{G} \times \mathrm{E}$ might help us form theory-based hypotheses, for example, by using assumptions on the biological functions of specific genetic markers in choosing which marker is likely to interact with a specific environment in predicting a specific outcome. Thus, complementary to an inductive strategy-in looking for underlying mechanisms after a $\mathrm{cG} \times \mathrm{E}$ interaction has been robustly identified, as proposed by Dodge (2009) — we propose a deductive strategy.

\section{Toward a Theoretical Framework: Three Possible Underlying Mechanisms}

We are not the first to stress the importance of theories about mechanisms underlying $\mathrm{cG} \times \mathrm{E}$ (e.g., Reiss and Leve 2007; Rutter et al. 2006; Salvatore and Dick 2015), but to date only few scholars have elaborated on specific hypotheses on such mechanisms (see Davies and Cicchetti 2013; Dodge 2009; Calkins et al. 2013). Here, we put forward three possible, non-exclusive, explanatory mechanisms underlying $\mathrm{G} \times \mathrm{E}$ in the development of externalizing behaviors. These mechanisms concern serotoninrelated emotional reactivity, dopamine-related reward sensitivity, and serotonin-related punishment sensitivity, and are based on associations previously established in the literature. Each mechanism takes the form of a mediated moderation model (i.e., the interaction between two variables affecting the mediator, which then affects a dependent variable, Morgan-Lopez and MacKinnon 2006; Muller et al. 2005), in which moderation by genotype is (partly) explained by a mediating process. The mediator is a partly heritable biopsychosocial function, which is shaped by countless previous interactions with the environment during early development (i.e., an entrained biopsychosocial trait, Dishion and Patterson 2006). Individual differences in these functions can both directly contribute to the development of externalizing behavior (e.g., as symptoms part of a diagnosis, such as impulsivity, irritability), as well as indirectly through the way children react to environmental adversity (e.g., heightened emotional reactivity to anger, lowered sensitivity to reward). In the case of $\mathrm{G} \times \mathrm{E}$ in the development of externalizing behavior, we assume that genetic make-up strengthens or weakens the effect of family adversity on externalizing problem behaviors, which is explained by individual differences in biopsychosocial functioning shaped by a combination of genetic predisposition and previous interactions with environmental adversity (see Fig. 1). Conform suggestions by Caspi and Moffitt (2006), for each mechanism
Fig. 1 Conceptual mode of gene-environment interactions and underlying mechanisms
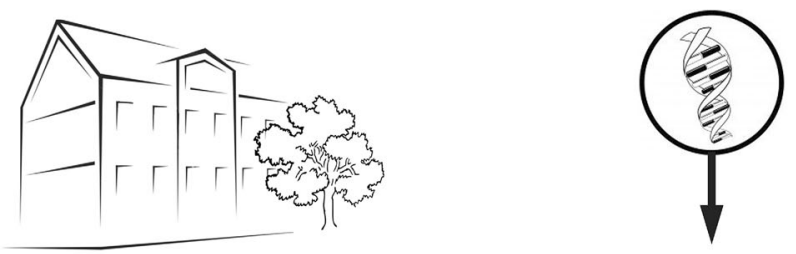

Genotype

Environment

Behavioral outcomes

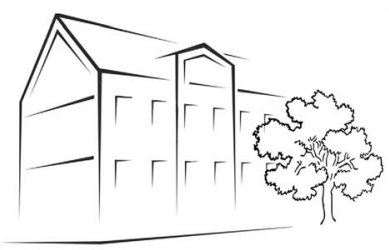

Environment
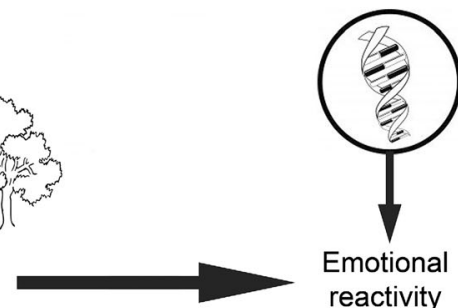

Genotype

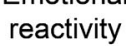

Behavioral outcomes 
we separately discuss evidence for the link between (1) externalizing behaviors (outcome) and the proposed mechanism, (2) genetics $(\mathrm{G})$ and the proposed mechanism, and (3) family adversity (E) and the proposed mechanism.

\section{Emotional Reactivity}

\section{Externalizing Behavior and Emotional Reactivity}

Individual differences in the form and intensity of reactions to emotional stimuli are at the core of temperament and personality research (Derryberry and Rothbart 1988) and are known risk factors in the development of externalizing behaviors (Scott and O'Connor 2012). Heightened emotional reactivity can function as an emotional liability that makes people more sensitive to negative emotional family environments (Sheese et al. 2009). Specifically, it may make people more likely to respond in affectively intense ways under stress. Indeed, in young children heightened emotional reactivity predicts temper tantrums (Giesbrecht et al. 2010). Research also shows that children's irritable temperament is significantly associated with their angry reactivity to parental conflict and eventually to externalizing symptoms (Davies et al. 2012). Finally, differences in reactivity to emotional stimuli have been associated with different forms of externalizing psychopathology (e.g., De Wied et al. 2006).

\section{Polymorphisms and Emotional Reactivity}

Emotional reactivity is often referred to as an individual's characteristic threshold, intensity, and duration of affective arousal (Rothbart and Derryberry 1981). In the neurobiological processing of emotional stimuli, the amygdala plays an important role (for a meta-analysis, see Costafreda et al. 2008). Differences in amygdala activity in reaction to emotional stimuli are associated with differences in imitation of emotional expressions, memory of emotional events, and social behavior (Decety 2010; Hare et al. 2008; Hariri and Holmes 2006; Pfeifer et al. 2008). The connectivity between the amygdala and the feedback circuit critical for emotion regulation is in turn shaped by variation in serotonin signaling (e.g., Pezawas et al. 2005).

Polymorphisms related to lower serotonin transport and uptake (specifically, the 5-HTTLPR S-allele) - and therefore higher serotonin availability-have been associated with heightened amygdala activity in response to emotional stimuli (see for meta-analyses Munafò et al. 2008; Murphy et al. 2013). Although the exact mechanisms by which these polymorphisms are linked to amygdala response are unknown (Kobiella et al. 2011), one possibility is that these polymorphisms are related to diminished regulation and therefore higher and less stable availability of serotonin, causing higher increases in neuronal activity —and therefore higher arousal—during activation (for a review see Yildirim and Derksen 2013). These polymorphisms might thus, through biological translation and transcription pathways, ultimately contribute to a heightened neuronal reactivity to emotional stimuli. People carrying such polymorphisms might experience more intense and prolonged arousal when processing emotional stimuli than people without these polymorphisms. In the long run, this may lead to an upregulated sensitivity for the effects of negative emotional stimuli and eventually lead to anger and irritability and the development of impulsive or reactive externalizing behavior (Miczek et al. 2002). Considering that this heightened emotional reactivity might manifest in irritable behavior in reaction to the environment, there is an important overlap with research on internalizing child behaviors. Irritability might therefore be, through emotional reactivity, an important underlying endophenotype to both oppositional behavior and child depression (Copeland et al. 2009; Stringaris et al. 2012).

\section{Family Adversity and Emotional Reactivity}

Environmental adversities such as harsh family emotional climates may also contribute to individual differences in emotional reactivity. The family is usually the first and most important context in which children learn how to recognize, interpret and manage other people's emotions (Dunn et al. 1991; Dunn and Brown 1994). Negative parental emotional expressivity was found to be negatively related to children's socioemotional competence and positively correlated with children's externalizing problems (Isley et al. 1999). Children's observations of marital conflict, for example, can lead to an increased sensitivity to anger cues (El-Sheikh et al. 1996). A recent meta-analysis found gray matter abnormalities in individuals exposed to childhood maltreatment, specifically in regions that are related to affect (Lim et al. 2014). Moreover, a whole-brain analysis showed that early family adversities differentially modify neural (i.e., amygdala and cortical) reactivity to emotional stimuli depending on 5-HTTLPR-genotype (Walsh et al. 2012). It might therefore be that repeated exposure to negative family emotional climates increases neurological arousal to such emotional stimuli, in some children more than in others. Furthermore, such climates might cause changes in neuropsychological (e.g., emotion and behavior regulation), and attention processes (Davies et al. 2006). It has been shown that negative environmental cues might differentially alter activity in brain regions related to emotional processing: Amygdala and hippocampus activation at rest was correlated positively with life stress in carriers of the S-allele, but negatively in LL-genotypes (Canli and Lesch 2007).

In sum, the literature reviewed shows that: (1) high emotional reactivity is a risk factor for irritable, 
oppositional, and reactively aggressive behavior; (2) serotonin might be an important regulator of neuronal reactivity to emotional stimuli, with a low regulating serotonergic system (or high and unstable levels of serotonin) relating to high emotional reactivity, and (3) a negative emotional family climate might contribute to a heightened emotional reactivity. Thus, exposure to negative family emotional climates might increase neurological arousal by emotional stimuli, specifically in children with higher and less stable serotonin availability (e.g., 5-HTTLPR S-allele; $M A O A$ low-activity allele). In turn, children experiencing such dual risk might develop a heightened emotional reactivity. As a consequence, they might show more symptoms of angry/irritable mood (see symptom clusters of ODD in DSM-5, American Psychiatric Association 2013) and reactive aggression, compared to children growing up without this genetic and/or environmental risk, specifically when they are exposed to negative emotions and/or a negative family emotional climate (i.e., in line with frustration-aggression model; Berkowitz 1989). We know little about whether such a heightened emotional reactivity is specific to negative emotions, or might be a general heightened reactivity to both positive and negative emotions. In case of the latter, these children might benefit relatively more from interventions targeting the family emotional climate (e.g., teaching parents emotion-regulation strategies or targeting marital conflict). Also, because these children experience increased emotional arousal, they might specifically benefit from interventions targeting emotion regulation. Or, in case of heightened emotional reactivity to specifically negative emotions, from interventions using anger management techniques.

All hypotheses discussed in this paper are best tested using a triangulation of research strategies (Dick 2011). Longitudinal designs can be used to disentangle the prospective relationships between specific family/adversity (e.g., parental stress, warmth/harshness), the mechanisms (e.g., sensitivity to anger cues), and externalizing behavior (e.g., irritability and aggression), using specific measures for the environmental and behavioral variables. Marker for individual differences in dopaminergic or serotonergic regulation can serve as a moderator variable to test whether these relations are indeed stronger for some individuals than others (see Davies and Cicchetti 2013). In the case of the mechanism of emotional reactivity, the reviewed literature suggests that genetic markers that are specifically related to less efficient regulation of serotonin (i.e., high and unstable levels of serotonin) might be important measures of such differences in emotional stimuli. It might therefore be necessary to use multiple genetic markers, haplotypes or genetic pathways (e.g., using not only genetic variation in the serotonin transporter gene, but also including genes coding for the synthesis and reuptake of serotonin such as the TPH1, HTRlA, and HTR2C) as constructs of genetic moderation. Findings should be replicated in independent samples (see also Asherson and Price 2012). Simultaneously, more focused designs could be used to further investigate the mechanisms on a micro level (see also Howe et al. 2010). In case of the mechanism of emotional reactivity, experimental designs could be used to observe children's emotional — and in turn behavioralreactions to different emotional climates when interacting with their caregiver(s) (for an overview on experimental studies on $\mathrm{cG} \times \mathrm{E}$, see Bakermans-Kranenburg and Van IJzendoorn 2015), for example, using facial electromyography (fEMG; e.g., Deschamps et al. 2012) or functional magnetic resonance imaging (fMRI, e.g., Canli et al. 2001) to measure the strength of children's reaction to emotional stimuli.

\section{Reward Sensitivity}

\section{Externalizing Behavior and Reward Sensitivity}

Reward insensitivity is related to externalizing behaviors through two different non-exclusive pathways. First, it is an important mechanism underlying differences in sensitivity to behavioral conditioning (Steinberg 2007). Insensitivity to reward might cause a lack of motivation to obtain ordinary or delayed rewards, resulting in an impaired social learning by stimulus-reward (Buckholtz et al. 2010). For example, aggressive boys with conduct problems have been found to show cardiac pre-ejection period (PEP) nonreactivity to monetary incentives, presumably indicating lowered reward sensitivity (Beauchaine et al. 2008). Second, low reward sensitivity may be related to excessive stimulation seeking (i.e., thrill- and sensation seeking) and egocentrically driven behavior (Quay 1988) as reaction to difficulties achieving a pleasant level of stimulation through regular sources (Matthys et al. 2013). Reward insensitivity might thus cause people to actively seek more powerful rewarding cues in their environment, ignoring negative cues, and not foreseeing long-term negative effects. In turn, this may be related to risk-taking and thrillseeking behaviors and an increased risk for addiction (Robinson and Berridge 2008; Volkow et al. 1997).

\section{Polymorphisms and Reward Sensitivity}

Low reward sensitivity might be related to a blunted response to ordinary reward cues in the brain. The perceived value of reward is regulated by dopamine, in that dopamine activity has direct rewarding effects (Pessiglione et al. 2006; Schultz 2010). Specifically, the number of available dopamine receptors affects the level of stimulation by dopamine after it is released. Lower amount of 
receptors could therefore result in a reduced salience of positive environmental stimuli, making people less able to derive reward from ordinary, everyday activities (Buckholtz et al. 2010; Sevy et al. 2006). Furthermore, low uptake of dopamine might reduce effects of rewards on decisions (i.e., reward based learning), but also decrease valence of delayed rewards in both rodents and humans (for a review see Comings and Blum 2000). It might be that people carrying polymorphisms related to lower density of dopamine receptors in the brain are less aroused when dopamine is released in reaction to (anticipated) reward stimuli. Polymorphisms regulating dopamine availability and uptake predict interpersonal differences in neurological reactivity to reward cues (Dreher et al. 2009; Lancaster et al. 2012). Also, when looking at multilocus composite scores (which theoretically identify dopamine signaling capacity in reward regions), there is support for low reward activity in people with low dopamine signaling capacities (Stice et al. 2012). Additionally, it has been shown that children carrying a dopamine transporter genotype composite score related to lower transcriptional efficacy (and thus lower dopamine availability in the synapse) show more behavioral problems when mothers are unresponsive, than children carrying other genotypes, specifically because they show more behavioral disinhibition (Davies et al. 2015). Polymorphisms related to low dopamine activity might thus, through biological translation and transcription pathways, ultimately contribute to a lower sensitivity to ordinary or delayed rewards, causing a need for continuous, direct, and more salient reinforcers to control behavior (Kobayashi and Schultz 2008).

\section{Family Adversity and Reward Sensitivity}

Environments in which rewarding stimuli are less available (e.g., lack of positive parenting, abusive families, social or economic deprivation) might also contribute to differences in reward sensitivity. An animal model, for example, showed that monkeys deprived of parenting seemed less able to learn from rewards (Pryce et al. 2004). In humans, we see that growing up in families with a low social economic status may trigger a preference for immediate rewards, eventually predicting risky behaviors (Griskevicius et al. 2011). Also, people coping with addiction often have a history of abuse and maltreatment as children (Masten 2007). It might therefore be that the absence or scarcity of rewarding stimuli, in relation to behavior learning, lowers sensitivity to daily rewards, for some children more than for others. This might cause a need for more direct and larger rewards, and therefore impaired social learning by stimulus-reward, and active rewardseeking behaviors.
In sum, the reviewed literature shows that: (1) lowered reward sensitivity can be a risk factor for specifically noncompliant, antisocial, risky, thrill-seeking behaviors, (2) lower dopamine uptake after it is being released is associated with a reduced salience of positive stimuli, and (3) a preference for direct, large, and powerful rewards can be triggered by environments in which rewarding cues are less available. Thus, the absence or scarcity of rewarding stimuli might lower children's sensitivity to daily rewards, specifically in children with low dopamine activity (e.g., COMT Val-allele, MAOA high-activity allele, DRD4 7-repeat allele, $D R D 2$ A1-allele, and $D A T$ 10-repeat allele). In turn, children experiencing such dual risk might develop a low sensitivity to typical environmental reinforcers (i.e., experiencing them as less rewarding). As a consequence, they might show more non-compliant, risky, and thrillseeking behavior, compared to children growing up without this genetic and/or environmental risk, specifically when the current environment does not offer them the necessary rewarding stimuli (e.g., specific praise and tangible rewards) or behavioral monitoring (i.e., short behavioral monitoring intervals). On the bright side, these children might respond specifically well to immediate versus postponed and strong versus weak reward. Therefore, using sufficient reward and interventions targeting reward-oriented parenting strategies, might be a very effective strategy to decrease problem behavior in these children. Also, if the emotional significance of the positive message of praise is less well processed, both verbal and nonverbal enthusiasm, accompanying praise and reward, would be particular relevant (Matthys et al. 2012). Furthermore, because these children are at risk for impulsive and risky behavior, these children might specifically benefit from interventions targeting behavioral control.

Experimental designs could be used to observe children's behavioral reactions to parenting practices that focus on reward, and if these reactions are indeed stronger in some children than in others. For example, using a genetically informed experiment in which parents are assigned to different conditions and either instructed to use praise or small tangible rewards to condition a specific behavior or to use their usual approach (i.e., micro trial, Howe et al. 2010). The reviewed literature suggests that genetic markers which are specifically related to low dopamine activity (i.e., less efficient transport, low amount of receptors) might be important genetic markers of these individual differences in reward sensitivity, specifically in combination with family adversity. In older children, computer tasks can be used to measure differences in reward sensitivity between genetic subgroups (similar designs have been successfully used to study $\mathrm{cG} \times \mathrm{E}$ with different predictors see e.g., Gallardo-Pujol et al. 2013). Another promising approach might be embedding non- 
genetic biological markers, such as electroencephalography (i.e., EEG) measures, to genetic research on externalizing behavior. EEG has received increased attention over the last few years as potential biomarker for psychopathology and treatment response (for a review see Loo et al. 2015). Previous studies indeed indicate that resting-state brain activity (specifically theta activity) is related to reinforcement learning, risky decision taking, and might therefore be a marker for specifically reward, but not punishment, sensitivity (e.g., Massar et al. 2014).

\section{Punishment Sensitivity}

\section{Externalizing Behavior and Punishment Sensitivity}

Individual differences in punishment sensitivity are mostly seen as differential responsiveness to fear conditioning (Eron 1997; Lykken 1957). Low punishment sensitivity may result in a lower concern about consequences of behavior. This may become manifest as disregard for aversive consequences of response choices (Fontaine 2006), in reward-driven behavior, and in difficulties changing one's behavior in response to punishment cues (Carlson et al. 2012; Santesso et al. 2011). Low punishment sensitivity is associated with aggression in childhood and criminal behavior in adulthood (Gao et al. 2010a, b). Also, children with ODD are less likely than controls (and than children with ADHD) to change behavior after it was punished (Humphreys and Lee 2011; Matthys et al. 2004). Longitudinal research further found that children with low levels of temperamental fear are less receptive to discipline techniques that are based upon punishment (Kochanska 1997). Research indicates that specific aspects of punishment insensitivity, namely low anxiety and sensitivity to aversive stimuli, and high reward dominance, are evident in clinical samples of adolescents (for an overview see Dadds and Salmon 2003).

\section{Polymorphisms and Punishment Sensitivity}

Low punishment sensitivity is a largely heritable factor consisting of a diverse but overlapping set of propensities including low arousal to aversive stimuli, fearlessness, and poor avoidance learning (Dadds and Salmon 2003). Several functional neuroimaging studies have shown that the amygdala and related structures are important in processing cues related to threat and fear (for a review see Davis and Whalen 2001). People high on externalizing behaviors possibly show reduced amygdala reactivity to-particularly negative-emotional stimuli (Blair 2008; Sterzer et al. 2005). This failure to be aroused by and learn from stressful stimuli or punishment may predispose individuals to deficient conscience development and poorly socialized behaviors (Kochanska et al. 2007).

Serotonin might act as a motivational opponent to dopamine (Daw et al. 2002) by modulating the impact of punishment-related (rather than reward-related) signals on learning and emotion (Cools et al. 2008). Children and adolescents showing high levels of externalizing behaviors seem to show altered serotonergic functioning (for a review see Matthys et al. 2013). In contrast to high and less stable serotonin availability underlying a heightened emotional reactivity, low and stable serotonin availability might underlie reduced punishment sensitivity. Indeed, 5HTTLPR L-allele carriers exhibit low amygdala activity in reaction to emotional stimuli (as low as $3 \%$ compared to $28 \%$ in S-allele carriers; see Munafò et al. 2008). Also, 5HTTLPR L-allele carriers showed impairments in avoidance learning and show overall lower fear responses, compared to S-carriers (Finger et al. 2006; Brocke et al. 2006). Low and stable serotonin availability possibly lowers the intensity and duration of emotional arousal, lowering stress sensitivity in reaction to emotional stimuli (for a review see Yildirim and Derksen 2013). These polymorphisms might thus, through biological translation and transcription pathways, ultimately contribute to lower arousal by aversive stimuli, and therefore insensitivity to punishing cues, such as anger and distress in others, as well as to aversive consequences following externalizing behavior. Given this possible pathway, it is not surprising that reduced punishment sensitivity has been suggested as a key factor in psychopathy (Frick and Ellis 1999). Parallels exist between research on psychopathy and the described literature on punishment sensitivity, showing similarities in behavioral traits, polymorphisms, brain functioning, and neuropsychological indicators (for reviews see Glenn 2011; Yildirim and Derksen 2013).

\section{Family Adversity and Punishment Sensitivity}

Although punishment sensitivity is mostly seen as a child factor it is also partly dependent on environmental factors (for an overview see Dadds and Salmon 2003). As early as the 1950s, it was found that animals raised in deprived environments show less intense reactions to pain stimuli (Nissen et al. 1951) and take longer to learn avoidance of painful stimuli (Melzack and Scott 1957). In humans, maltreated children show a disregard for risk of punishment when responding in a reward-oriented task (Guyer et al. 2006). It might therefore be that in some children, more than in others, consistent harsh punishment or punishment mixed with reward reduces their reactivity to punishment. This makes it difficult to further socialize these children through strategies that rely on motivation to avoid punishment instead of to obtain reward. 
In sum, the reviewed literature shows that (1) low punishment sensitivity is a risk for-specifically proactive-externalizing behaviors, (2) serotonin acts as a motivational opponent to dopamine in that it regulates the impact of punishment-related signals in which low/ stable levels of serotonin are related to low punishment sensitivity, and (3) harsh or unpredictable family environments can increase insensitivity to punishment and therefore increase reward-oriented behaviors. Thus, children experiencing maltreatment, harsh punishment, or punishment mixed with reward might develop a blunted reactivity to negative emotional arousal and punishment, specifically when they have low and stable levels of serotonin availability (e.g., the 5-HTTLPR L-allele or MAOA high-activity allele). In turn, children experiencing such dual risk might be less sensitive to punishment-oriented strategies and will therefore show more antisocial behavior compared to children growing up without this genetic and/or environmental risk, specifically when the current environment relies on harsh and/or unpredictable punishment for socialization. Eventually, this low reactivity and poor conditionality through punishment might induce proactive, instrumental, and maybe even predatory antisocial behavior later in adulthood, forming a risk factor for proactive agression, antisocial personalities and psychopathic traits. Also, these children might be at risk for escalating cycles of punishment, as milder forms of punishment may be less effective and parents might get frustrated. On the bright side, interventions focusing on relabeling inappropriate behaviors into positive opposites, and using praise and token economy to positively reinforce the appropriate behaviors, might be especially effective for this group of children (see also Matthys et al. 2012). Also, because these children might be at risk for deficiencies in emotion recognition, empathy, and perspective taking, they might specifically benefit from cognitive behavioral treatment.

Randomized controlled trials using a parenting intervention to reduce punishment-oriented strategies can be used to test this punishment sensitivity hypothesis. Such RCT's could be used to explore whether such interventions have different effects on externalizing behavior between different genetic subgroups (similar designs have been previously used see Bakermans-Kranenburg and Van IJzendoorn 2015). The reviewed literature suggests that genetic markers which are specifically related to low and stable levels of serotonin availability (i.e., low levels of synthesis, high levels of reuptake and degradation) might be important genetic markers of these individual differences in punishment sensitivity, specifically in combination with family adversity. Within more focused experimental research, different physiological measures could be used to assess punishment sensitivity. For example, a previous study demonstrated the value of startle reactivity measures for differentiating between mechanisms underlying the development of different externalizing phenotypes (Fanti et al. 2015). Since the amygdala plays a role in punishment decision-making (e.g., Treadway et al. 2014), fMRI might be a promising additional measure of individual differences in punishment sensitivity (e.g., Gregory et al. 2015).

\section{General Discussion}

In part one of our paper, we systematically reviewed 53 papers on $\mathrm{cG} \times \mathrm{E}$ in externalizing behaviors, showing many significant, but also contrasting, findings. Large variations in methodologies (e.g., sample size and composition) and differences in-the specificity of-conceptualizations of both family adversity and externalizing behaviors make it difficult to integrate these findings and make cross-study comparisons. This essentially means that many $\mathrm{cG} \times \mathrm{E}$ studies are oftentimes built on earlier findings of not necessarily comparable studies, and thus not serving to create a coherent base of literature. One way to create more comparable results, and draw solid conclusions, is by forming a priori hypotheses on how specific family adversity factors interacting with specific polymorphisms in specific samples predict specific behavior. Researchers should be able to justify why they are studying these specific genes, this environmental risk, this behavioral outcome, and why they measured it with these specific instruments (see also Dick et al. 2015). Therefore, it is imperative to move toward a deductive strategy by forming theories on the interaction between genes and environment, which not only stem from $\mathrm{cG} \times \mathrm{E}$ research, but also from literature on behavior development, genetics, and neurobiology. The added bonus of working with a sound theoretical framework is that it might help to diminish publication bias by enabling us to confirm or reject theory-based hypotheses and thus increase the relevance of "null findings" (i.e., nonsignificant interactions).

In part two of our paper, we therefore tried to contribute to the literature by proposing three hypotheses on nonexclusive mechanisms underlying $\mathrm{G} \times \mathrm{E}$ in externalizing behavior. Concrete evidence emerged from the literature review for the mechanisms of emotional reactivity, reward sensitivity, and punishment sensitivity. These mechanisms most likely underlie specific traits rather than diagnoses or complex behavioral clusters. Because of high comorbidity and overlap in symptomology and etiology within externalizing behavior, both equifinality and multi-finality is to be expected. Different genetic and neuropsychological pathways might contribute to the same diagnosis (i.e., equifinality). For example, $\mathrm{CD}$ is associated with $\mathrm{cG} \times \mathrm{E}$ including the MAOA (Foley et al. 2004), as well as the DAT1 and 5-HTTLPR (Sonuga-Barke et al. 2009). At the 
same time, a single polymorphism may contribute to different behavior clusters (i.e., multi-finality). For example, the 5-HTTLPR S-allele predicts heightened emotional reactivity, which includes irritability, a core symptom of both depression and ODD in children (Copeland et al. 2009). It could thus be that serotonin-related heightened emotional reactivity underlies both disorders through the same distinct genetic underpinnings for this trait (Stringaris et al. 2012). The term "risk" allele is therefore questionable in the context of $\mathrm{cG} \times \mathrm{E}$. Indeed, some alleles have even been shown to "protect" from certain adversities and have been related to children's heightened susceptibility to parenting interventions (Bakermans-Kranenburg et al. 2008). Although this paper focused on differential negative effects of family adversities (i.e., dual risk), the described mechanisms might work both ways, in such that the same mechanisms might lead to differential pro-social behavioral outcomes under environmental enrichment (i.e., differential susceptibility, Belsky 2005). Also, it is important to note that the proposed mechanisms should be seen as possible candidates, but neither as comprehensive frameworks in explaining externalizing behaviors through $\mathrm{cG} \times \mathrm{E}$ nor as providing a quick fix to overcome all growing pains of this field. Specifically, the role of executive functions, meta-cognitive functions, and morality in these mechanisms needs further elaboration. Deviances in the processing of reward and punishment cues may, for example, affect cognitive functions such as decision-making (Matthys et al. 2013). A recent study found that emotion regulation through cognitive reappraisal serves as a buffer in the association between 5-HTTLPR, environmental stressors, and psychopathology (Ford et al. 2014). Also, to narrow the scope of our literature overview, our review focuses solely on family adversity. However, the effects of specific family adversity might change over time (Choe et al. 2014; Reiss et al. 2013; Windhorst et al. 2015). Specifically, environmental adversity measures outside the family might become increasingly important when children grow older. Indeed, a recent study found differential associations of a polygenetic score with adolescent externalizing behavior when including different environmental adversities, with stronger effects for peer substance use than for parental monitoring (Salvatore et al. 2014). Moreover, environmental risk factors are not independent factors, and together form the broader environmental context children grow up in (see for a review of this issue Boardman et al. 2013). Another limitation of our review paper is that the interplay between genes and the environment might be too complex to be explained through moderation (or $\mathrm{G} \times \mathrm{E}$ ) alone. We need to take into account that genes might, for example, also control the exposure to certain environments (i.e., gene-environment correlation, see Plomin and Simpson 2013). For example, children low on reward sensitivity might actively seek out risky environments and children low on punishment sensitivity might evoke harsh parenting behavior. Furthermore, current knowledge on functional expressions of the polymorphisms in the human brain is limited (Balciuniene et al. 2002). Multiple inherited DNA elements can influence transcription and expression of a protein (see also Rutter 2007). In the search of underlying mechanisms, it might therefore be important to relate these mechanisms to one or more functional genetic pathways or haplotypes (see also Plomin and Simpson 2013). More recent studies on the functional effects of the $M A O A$, for example, showed no significant association of a single polymorphism with expression levels or enzyme activity in the human brain, but did find such associations with a haplotype (Balciuniene et al. 2002). Although not reviewed in this paper, some of the reviewed studies found interactions among multiple candidate genes (often with very different functions). For example, Simons et al. (2011) found an interaction between the DRD4 (coding for dopamine receptors), 5-HTTLPR (coding for serotonin transporters) polymorphisms, and social conditions in predicting aggression. It is difficult to address functional mechanisms for such polygenic effects of functionally diverse polymorphisms. One possibility is that such polygenic effects indicate cumulative genetic vulnerability or a complex interplay of genes on regulation of different neurotransmitters (e.g., they might bring about a certain balance in neurotransmitter activity). There are, however, also examples of cumulative effect of functionally related groups of genes. For example, Stephens et al. (2012) found a direct association between multiple SNP's in the CHRNA5/CHRNA3/CHRNB4 (i.e., neuronal nicotinic acetylcholine receptor) gene cluster and externalizing behavior.

Another important issue for future research is that, specifically in early development, differential developmental outcomes might be caused by environmental influences that alter the functional activity of genes without altering the sequence (i.e., epigenetics, see Roth 2013). DNA methylation, for example, mediates the relation between a polymorphism and developmental outcomes by changing the expression of the gene (Van IJzendoorn et al. 2011). Candidate gene approaches have been criticized for their rather naïve view on the biological function of single genes (e.g., Szyf and Bick 2013), and technological progress enables us to use more advanced strategies to study the role of genetics in externalizing behavior (e.g., genome-wide association studies (GWAS), haplotype analyses, genetic pathways, epigenetics). These approaches can deepen and extend our knowledge on the role of genetics in the development of externalizing behavior. However, it is important to note that these strategies do not necessarily yield more consistent findings (Aebi et al. 2015; Chabris 
et al. 2013; Neale et al. 2010). For example, results of a GWAS study on CD by Dick et al. (2011) showed no overlap with findings of a GWAS study on CD by Anney et al. (2008). Also, due to a lack of knowledge on the functions of many "new" genes, it is sometimes not possible to interpret findings and describe functional involvement of these genes in the development of specific behavior (e.g., Dick et al. 2011; Pappa et al. 2015). Moreover, the same recommendations on using theorybased a priori hypotheses apply to studies using such more advanced methods. Studies on the function, expression, and effects of single polymorphism can possibly be seen as "links in a chain," functioning as important stepping-stones for moving us forward. Polymorphisms having a functional impact on gene expression can function as markers for more complex processes underlying individual differences in reaction to family adversity, and therefore provide us with clues on possible underlying mechanisms. Such a "reversed endophenotype" (see also Loo et al. 2015) approach could also help us in the search for less intrusive markers for differential susceptibility to specific environmental adversity, and in turn give us clues for research and intervention strategies.

\section{Conclusion}

Findings on $\mathrm{cG} \times \mathrm{E}$ in externalizing behaviors are heterogeneous. However, large methodological differences between studies make it difficult to integrate findings and draw solid conclusions on the role of $\mathrm{cG} \times \mathrm{E}$ in externalizing behavior. Hypotheses on underlying mechanisms of $\mathrm{cG} \times \mathrm{E}$ can serve as a conceptual framework for gaining a deeper understanding of these interactions, specifying our research strategies accordingly, and substantiate the findings reported so far. Hypotheses that derive from these frameworks should be tested, using a multidisciplinary (i.e., Play nice in the sandbox, Dick 2011) triangulation of research strategies (Overbeek et al. 2012). Although this review raised a series of important issues in the field of $\mathrm{cG} \times \mathrm{E}$ that need to be resolved, it also bears an optimistic message: The literature holds many clues on possible mechanisms. Insight in the underlying mechanisms can possibly help us interpret the intriguing, but inconsistent, findings on $\mathrm{cG} \times \mathrm{E}$ and enhance their empirical and clinical implications. It can point us in the direction of differential pathways leading to externalizing behaviors. And though not directly implementable, it can provide us with more insight in individual differences in the development of externalizing behavior. Eventually, knowledge on specific $\mathrm{cG} \times \mathrm{E}$ and their mechanisms might, for example, enable us to better predict which children are specifically vulnerable in which developmental period and target them using personalized interventions, not only in terms of clinical focus (i.e., based on specific mechanisms at work) (Matthys et al. 2012), but also in terms of intensity and duration (i.e., based on differences in susceptibility).

Acknowledgments We thank the contacted authors for their feedback on Table 1 and suggestions for additional studies to include. We thank Rabia Chhangur, Prof. Luc Goossens, Loes Keijsers, Ph.D., Odilia Laceulle, Ph.D., Hilde Schuiringa, Ph.D., and Meike Slagt for commenting on an earlier version of this paper and Jacqueline Vink, Ph.D. and Maaike Verhagen, Ph.D. for commenting on the description of the genes. Geertjan Overbeek was supported by a VIDI grant 452-10-005 of the Netherlands Organization for Scientific Research during the preparation of this manuscript.

\section{Compliance with Ethical Standards}

Conflict of interest The Authors declare no conflict of interest.

Open Access This article is distributed under the terms of the Creative Commons Attribution 4.0 International License (http://crea tivecommons.org/licenses/by/4.0/), which permits unrestricted use, distribution, and reproduction in any medium, provided you give appropriate credit to the original author(s) and the source, provide a link to the Creative Commons license, and indicate if changes were made.

\section{References}

Aebi, M., Van Donkelaar, M. M., Poelmans, G., Buitelaar, J. K., Sonuga-Barke, E. J., Stringaris, A., et al. (2015). Gene-set and multivariate genome-wide association analysis of oppositional defiant behavior subtypes in attention-deficit/hyperactivity disorder. American Journal of Medical Genetics Part B: Neuropsychiatric Genetics, 9999, 1-16. doi:10.1002/ajmg.b.32346.

Agnafors, S., Comasco, E., Bladh, M., Sydsjo, G., DeKeyser, L., Oreland, L., \& Svedin, C. G. (2013). Effect of gene, environment and maternal depressive symptoms on pre-adolescence behavior problems-A longitudinal study. Child and Adolescent Psychiatry and Mental Health, doi:10.1186/1753-2000-7-10.

American Psychiatric Association. (2013). Diagnostic and statistical manual of mental disorders (5th ed.). Washington, DC: Author.

Anney, R. J., Lasky-Su, J., Ó’Dúshláine, C., Kenny, E., Neale, B. M., Mulligan, A., et al. (2008). Conduct disorder and ADHD: Evaluation of conduct problems as a categorical and quantitative trait in the international multicentre ADHD genetics study. American Journal of Medical Genetics Part B: Neuropsychiatric Genetics, 147(8), 1369-1378. doi:10.1002/ajmg.b.30871.

Asghari, V., Sanyal, S., Buchwaldt, S., Paterson, A., Jovanovic, V., \& Van Tol, H. H. (1995). Modulation of intracellular cyclic AMP levels by different human dopamine D4 receptor variants. Journal of Neurochemistry, 65(3), 1157-1165. doi:10.1046/j. 14714159.1995.65031157.x.

Asherson, P., \& Price, T. S. (2012). Commentary: Replication, replication, replication: The continued need to substantiate GxE effects in child psychopathology-A response to Laucht et al. 2012. Journal of Child Psychology and Psychiatry, 53, 360-362. doi:10.1111/j.1469-7610.2012.02534.x.

Åslund, C., Nordquist, N., Comasco, E., Leppert, J., Oreland, L., \& Nilsson, K. W. (2011). Maltreatment, MAOA, and delinquency: Sex differences in gene-environment interaction in a large population-based cohort of adolescents. Behavior Genetics, 41, 262-272. doi:10.1007/s10519-010-9356-y. 
Bakermans-Kranenburg, M. J., \& Van IJzendoorn, M. H. (2006). Gene-environment interaction of the dopamine D4 receptor (DRD4) and observed maternal insensitivity predicting externalizing behavior in preschoolers. Developmental Psychobiology, 48(5), 406-409. doi:10.1002/dev.20152.

Bakermans-Kranenburg, M. J., \& Van IJzendoorn, M. H. (2011). Differential susceptibility to rearing environment depending on dopamine-related genes: New evidence and a meta-analysis. Development and Psychopathology, 23(01), 39-52. doi:10.1017/ S0954579410000635.

Bakermans-Kranenburg, M. J., \& Van IJzendoorn, M. (2015). The hidden efficacy of interventions: Gene $\times$ environment experiments from a differential susceptibility perspective. Annual Review of Psychology, 66, 11.1-11.29. doi:10.1146/annurevpsych010814-015407.

Bakermans-Kranenburg, M. J., Van IJzendoorn, M. H., Pijlman, F. T., Mesman, J., \& Juffer, F. (2008). Experimental evidence for differential susceptibility: dopamine D4 receptor polymorphism (DRD4 VNTR) moderates intervention effects on toddlers' externalizing behavior in a randomized controlled trial. Developmental Psychology, 44(1), 293-300. doi:10.1037/0012-1649. 44.1.293.

Balciuniene, J., Emilsson, L., Oreland, L., Pettersson, U., \& Jazin, E. (2002). Investigation of the functional effect of monoamine oxidase polymorphisms in human brain. Human Genetics, 110(1), 1-7. doi:10.1007/s00439-001-0652-8.

Battaglia, M. (2012). Challenges in the appraisal and application of gene-environment interdependence. European Journal of Developmental Psychology, 9(4), 419-425. doi:10.1080/17405629. 2012.689819.

Beach, S. R., Brody, G. H., Gunter, T. D., Packer, H., Wernett, P., \& Philibert, R. A. (2010). Child maltreatment moderates the association of MAOA with symptoms of depression and antisocial personality disorder. Journal of Family Psychology, 24(1), 12-20. doi:10.1037/a0018074.

Beauchaine, T. P., Hong, J., \& Marsh, P. (2008). Sex differences in autonomic correlates of conduct problems and aggression. Journal of the American Academy of Child and Adolescent Psychiatry, 47(7), 788-796. doi:10.1097/CHI.Ob013e318172ef4b.

Beaver, K. M., Gibson, C. L., DeLisi, M., Vaughn, M. G., \& Wright, J. P. (2012). The interaction between neighborhood disadvantage and genetic factors in the prediction of antisocial outcomes. Youth Violence and Juvenile Justice, 10(1), 25-40. doi:10.1177/ 1541204011422085.

Belsky, J. (2005). Differential susceptibility to rearing influence. In B. Ellis \& D. Bjorklund (Eds.), Origins of the social mind: Evolutionary psychology and child development (pp. 139-163). New York: Guildford.

Belsky, J., Bakermans-Kranenburg, M. J., \& Van IJzendoorn, M. H. (2007). For better and for worse differential susceptibility to environmental influences. Current Directions in Psychological Science, 16(6), 300-304. doi:10.1111/j.1467-8721.2007.00525.x.

Belsky, J., \& Pluess, M. (2013). Beyond risk, resilience, and dysregulation: Phenotypic plasticity and human development. Development and Psychopathology, 25(4pt2), 1243-1261. doi:10.1017/S095457941300059X.

Berkowitz, L. (1989). Frustration-aggression hypothesis: Examination and reformulation. Psychological Bulletin, 106(1), 59-73. doi:10.1037/0033-2909.106.1.59.

Bhaskar, L. V., Thangaraj, K., Wasnik, S., Singh, L., \& Raghavendra Rao, V. (2012). Dopamine transporter (DAT1) VNTR polymorphism and alcoholism in two culturally different populations of south India. The American Journal on Addictions, 21(4), 343-347. doi:10.1111/j.1521-0391.2012.00244.x.

Blair, R. (2008). The amygdala and ventromedial prefrontal cortex: Functional contributions and dysfunction in psychopathy.
Philosophical Transactions of the Royal Society B: Biological Sciences, 363(1503), 2557-2565. doi:10.1098/rstb.2008.0027.

Boardman, J. D., Daw, J., \& Freese, J. (2013). Defining the environment in gene-environment research: Lessons from social epidemiology. American Journal of Public Health, 103(S1), 64-72. doi:10.2105/AJPH.2013.301355.

Boardman, J. D., Menard, S., Roettger, M. E., Knight, K. E., Boutwell, B. B., \& Smolen, A. (2014). Genes in the dopaminergic system and delinquent behaviors across the life course the role of social controls and risks. Criminal Justice and Behavior, 41, 713-731. doi:10.1177/0093854813514227.

Brocke, B., Armbruster, D., Muller, J., Hensch, T., Jacob, C. P., Lesch, K. P., et al. (2006). Serotonin transporter gene variation impacts innate fear processing: Acoustic startle response and emotional startle. Molecular Psychiatry, 11(12), 1106-1112. doi:10.1038/sj.mp.4001908.

Buckholtz, J. W., Treadway, M. T., Cowan, R. L., Woodward, N. D., Benning, S. D., Li, R., et al. (2010). Mesolimbic dopamine reward system hypersensitivity in individuals with psychopathic traits. Nature Neuroscience, 13(4), 419-421. doi:10.1038/nn.2510.

Burt, S. A. (2009). Rethinking environmental contributions to child and adolescent psychopathology: A meta-analysis of shared environmental influences. Psychological Bulletin, 135(4), 608-637. doi:10.1037/a0015702.

Byrd, A. L., \& Manuck, S. B. (2014). MAOA, childhood maltreatment, and antisocial behavior: Meta-analysis of a gene-environment interaction. Biological Psychiatry, 75(1), 9-17. doi:10. 1016/j.biopsych.2013.05.004.

Calkins, S. D., Propper, C., \& Mills-Koonce, W. R. (2013). A biopsychosocial perspective on parenting and developmental psychopathology. Development and Psychopathology, 25, 1399-1414. doi:10.1017/S0954579413000680.

Canli, T., \& Lesch, K. P. (2007). Long story short: the serotonin transporter in emotion regulation and social cognition. Nature Neuroscience, 10(9), 1103-1109. doi:10.1038/nn1964.

Canli, T., Zhao, Z., Desmond, J. E., Kang, E., Gross, J., \& Gabrieli, J. D. (2001). An fMRI study of personality influences on brain reactivity to emotional stimuli. Behavioral Neuroscience, 115(1), 33-42. doi:10.1037//0735-7044.115.1.33.

Carlson, S. R., Pritchard, A. A., \& Dominelli, R. M. (2012). Externalizing behavior, the UPPS-P impulsive behavior scale and reward and punishment sensitivity. Personality and Individual Differences, 54(2), 202-207. doi:10.1016/j.paid.2012.08. 039.

Carrel, L., \& Willard, H. F. (2005). X-inactivation profile reveals extensive variability in $\mathrm{X}$-linked gene expression in females. Nature, 434(7031), 400-404. doi:10.1038/nature03479.

Caspi, A., Hariri, A. R., Holmes, A., Uher, R., \& Moffitt, T. E. (2010). Genetic sensitivity to the environment: The case of the serotonin transporter gene and its implications for studying complex diseases and traits. The American Journal of Psychiatry, 167(5), 509-527. doi:10.1176/appi.ajp.2010.09101452.

Caspi, A., McClay, J., Moffitt, T. E., Mill, J., Martin, J., Craig, I. W., et al. (2002). Role of genotype in the cycle of violence in maltreated children. Science, 297(5582), 851-854. doi:10.1126/ science. 1072290.

Caspi, A., \& Moffitt, T. E. (2006). Gene-environment interactions in psychiatry: Joining forces with neuroscience. Nature Reviews Neuroscience, 7(7), 583-590. doi:10.1038/nrn1925.

Chabris, C. F., Lee, J. J., Benjamin, D. J., Beauchamp, J. P., Glaeser, E. L., Borst, G., et al. (2013). Why it is hard to find genes associated with social science traits: Theoretical and empirical considerations. American Journal of Public Health, 103(S1), 152-166. doi:10.2105/AJPH.2013.301327.

Chen, J., Lipska, B. K., Halim, N., Ma, Q. D., Matsumoto, M., Melhem, S., et al. (2004). Functional analysis of genetic 
variation in catechol- $O$-methyltransferase $(C O M T)$ : Effects on mRNA, protein, and enzyme activity in postmortem human brain. The American Journal of Human Genetics, 75(5), 807-821. doi:10.1086/425589.

Choe, D. E., Shaw, D. S., Hyde, L. W., \& Forbes, E. E. (2014). Interactions between monoamine oxidase $\mathrm{A}$ and punitive discipline in African American and Caucasian men's antisocial behavior. Clinical Psychological Science, 2, 591-601. doi:10. 1177/2167702613518046.

Cicchetti, D., Rogosch, F. A., \& Thibodeau, E. L. (2012). The effects of child maltreatment on early signs of antisocial behavior: Genetic moderation by tryptophan hydroxylase, serotonin transporter, and monoamine oxidase A genes. Development and Psychopathology, 24(3), 907-928. doi:10.1017/S0954579412 000442.

Comings, D. E., \& Blum, K. (2000). Reward deficiency syndrome: Genetic aspects of behavioral disorders. Progress in Brain Research, 126, 325-341. doi:10.1016/S0079-6123(00)26022-6.

Cools, R., Roberts, A. C., \& Robbins, T. W. (2008). Serotoninergic regulation of emotional and behavioural control processes. Trends in Cognitive Sciences, 12(1), 31-40. doi:10.1016/j.tics. 2007.10.011.

Copeland, W. E., Shanahan, L., Costello, E. J., \& Angold, A. (2009). Childhood and adolescent psychiatric disorders as predictors of young adult disorders. Archives of General Psychiatry, 66(7), 764-772. doi:10.1001/archgenpsychiatry.2009.85.

Costafreda, S. G., Brammer, M. J., David, A. S., \& Fu, C. H. (2008). Predictors of amygdala activation during the processing of emotional stimuli: A meta-analysis of 385 PET and fMRI studies. Brain Research Reviews, 58(1), 57-70. doi:10.1016/j. brainresrev.2007.10.012.

Costas, J., Sanjuán, J., Ramos-Ríos, R., Paz, E., Agra, S., Ivorra, J. L., et al. (2011). Heterozygosity at catechol- $O$-methyltransferase Val158Met and schizophrenia: New data and meta-analysis. Journal of Psychiatric Research, 45(1), 7-14. doi:10.1016/j. jpsychires.2010.04.021.

Dadds, M. R., \& Salmon, K. (2003). Punishment insensitivity and parenting: Temperament and learning as interacting risks for antisocial behavior. Clinical Child and Family Psychology Review, 6(2), 69-86. doi:10.1023/A:1023762009877.

Davies, P. T., \& Cicchetti, D. (2013). How and why does the 5-HTTLPR gene moderate associations between maternal unresponsiveness and children's disruptive problems? Child Development, 85(2), 484-500. doi:10.1111/cdev.12148.

Davies, P., Cicchetti, D., \& Hentges, R. F. (2015). Maternal unresponsiveness and child disruptive problems: The interplay of uninhibited temperament and dopamine transporter genes. Child Development, 86(1), 63-79. doi:10.1111/cdev.12281.

Davies, P. T., Cicchetti, D., \& Martin, M. J. (2012). Toward greater specificity in identifying associations among interparental aggression, child emotional reactivity to conflict, and child problems. Child Development, 83(5), 1789-1804. doi:10.1111/j. 1467-8624.2012.01804.x.

Davies, P. T., Sturge-Apple, M. L., Winter, M. A., Cummings, E. M., \& Farrell, D. (2006). Child adaptational development in contexts of interparental conflict over time. Child Development, 77(1), 218-233. doi:10.1111/j.1467-8624.2006.00866.x.

Davis, M., \& Whalen, P. J. (2001). The amygdala: Vigilance and emotion. Molecular Psychiatry, 6(1), 13-34. doi:10.1038/sj.mp. 4000812 .

Daw, N. D., Kakade, S., \& Dayan, P. (2002). Opponent interactions between serotonin and dopamine. Neural Networks, 15(4), 603-616. doi:10.1016/S0893-6080(02)00052-7.

De Wied, M., Van Boxtel, A., Zaalberg, R., Goudena, P. P., \& Matthys, W. (2006). Facial EMG responses to dynamic emotional facial expressions in boys with disruptive behavior disorders. Journal of Psychiatric Research, 40(2), 112-121. doi:10.1016/j.jpsychires.2005.08.003.

Deater-Deckard, K., \& Dodge, K. A. (1997). Externalizing behavior problems and discipline revisited: Nonlinear effects and variation by culture, context, and gender. Psychological Inquiry, 8(3), 161-175. doi:10.1207/s15327965pli08031.

Decety, J. (2010). The neurodevelopment of empathy in humans. Developmental Neuroscience, 32(4), 257-267. doi:10.1159/ 000317771.

Deckert, J., Catalano, M., Syagailo, Y. V., Bosi, M., Okladnova, O., Di Bella, D., et al. (1999). Excess of high activity monoamine oxidase A gene promoter alleles in female patients with panic disorder. Human Molecular Genetics, 8(4), 621-624. doi:10. 1093/hmg/8.4.621.

DeLisi, M., Beaver, K. M., Vaughn, M. G., \& Wright, J. P. (2009). All in the family gene $x$ environment interaction between DRD2 and criminal father is associated with five antisocial phenotypes. Criminal Justice and Behavior, 36(11), 1187-1197. doi:10.1177/0093854809342884.

Denney, R. M., Koch, H., \& Craig, I. W. (1999). Association between monoamine oxidase A activity in human male skin fibroblasts and genotype of the MAOA promoter-associated variable number tandem repeat. Human Genetics, 105(6), 542-551. doi:10.1007/s004399900183.

Derringer, J., Krueger, R. F., Irons, D. E., \& Iacono, W. G. (2010). Harsh discipline, childhood sexual assault, and MAOA genotype: An investigation of main and interactive effects on diverse clinical externalizing outcomes. Behavior Genetics, 40, 639-648. doi:10.1007/s10519-010-9358-9.

Derryberry, D., \& Rothbart, M. K. (1988). Arousal, affect, and attention as components of temperament. Emotions, Cognition, and Behavior, 55(6), 985. doi:10.1037/00223514.55.6.958.

Deschamps, P., Schutte, I., Kenemans, J., Matthys, W., \& Schutter, D. (2012). Electromyographic responses to emotional facial expressions in 6-7 year olds: A feasibility study. International Journal of Psychophysiology, 85(2), 195-199. doi:10.1016/j.ijpsycho. 2012.05.004.

Dick, D. M. (2011). An interdisciplinary approach to studying geneenvironment interactions: From twin studies to gene identification and back. Research in Human Development, 8(3-4), 211-226. doi:10.1080/15427609.2011.625317.

Dick, D. M., Agrawal, A., Keller, M. C., Adkins, A., Aliev, F., Monroe, S., et al. (2015). Candidate gene-environment interaction research: Reflections and recommendations. Perspectives on Psychological Science, 10, 37-59. doi:10.1177/1745691614 556682.

Dick, D. M., Aliev, F., Krueger, R. F., Edwards, A., Agrawal, A., Lynskey, M., et al. (2011). Genome-wide association study of conduct disorder symptomatology. Molecular Psychiatry, 16(8), 800-808. doi:10.1038/mp.2010.73.

Dishion, T. J., \& Patterson, G. R. (2006). The development and ecology of antisocial behavior. In D. Cicchetti \& D. J. Cohen (Eds.), Developmental psychopathology: Vol. 3. risk, disorder, and adaptation (2nd ed., pp. 503-541). Hoboken, NJ: Wiley.

Dmitrieva, J., Chen, C., Greenberger, E., Ogunseitan, O., \& Ding, Y. (2011). Gender-specific expression of the DRD4 gene on adolescent delinquency, anger and thrill seeking. Social Cognitive and Affective Neuroscience, 6(1), 82-89. doi:10.1093/scan/ nsq020.

Dodge, K. A. (2009). Mechanisms of gene-environment interaction effects in the development of conduct disorder. Perspectives on Psychological Science, 4(4), 408-414. doi:10.1111/j.1745-6924. 2009.01147.x.

Drabant, E. M., Hariri, A. R., Meyer-Lindenberg, A., Munoz, K. E., Mattay, V. S., Kolachana, B. S., et al. (2006). Catechol $O$ methyltransferase val158met genotype and neural mechanisms 
related to affective arousal and regulation. Archives of General Psychiatry, 63(12), 1396-1406. doi:10.1001/archpsyc.63.12. 1396.

Dreher, J., Kohn, P., Kolachana, B., Weinberger, D. R., \& Berman, K. F. (2009). Variation in dopamine genes influences responsivity of the human reward system. Proceedings of the National Academy of Sciences, 106(2), 617-622. doi:10.1073/pnas. 0805517106.

Ducci, F., Enoch, M. A., Hodgkinson, C., Xu, K., Catena, M., Robin, R. W., \& Goldman, D. (2007). Interaction between a functional $M A O A$ locus and childhood sexual abuse predicts alcoholism and antisocial personality disorder in adult women. Molecular Psychiatry, 13, 334-347. doi:10.1038/sj.mp.4002034.

Duncan, L. E., \& Keller, M. C. (2011). A critical review of the first 10 years of candidate gene-by-environment interaction research in psychiatry. The American Journal of Psychiatry, 168(10), 1041-1049. doi:10.1176/appi.ajp.2011.11020191.

Dunn, J., \& Brown, J. (1994). Affect expression in the family, children's understanding of emotions, and their interactions with others. Merrill-Palmer Quarterly (1982), 40(1), 120-137. Retrieved from http://www.jstor.org/stable/23087911

Dunn, J., Brown, J., \& Beardsall, L. (1991). Family talk about feeling states and children's later understanding of others' emotions. Developmental Psychology, 27(3), 448-455. doi:10.1037/00121649.27.3.448.

Edwards, A. C., Dodge, K. A., Latendresse, S. J., Lansford, J. E., Bates, J. E., Pettit, G. S., et al. (2010). MAOA-uVNTR and early physical discipline interact to influence delinquent behavior. Journal of Child Psychology and Psychiatry, 51, 679-687. doi:10.1111/j.1469-7610.2009.02196.x.

Eisenberg, D., MacKillop, J., Modi, M., Beauchemin, J., Dang, D., Lisman, S. A., et al. (2007). Examining impulsivity as an endophenotype using a behavioral approach: A DRD2 TaqI A and DRD4 48-bp VNTR association study. Behavior and Brain Functions, 3(e2), e2. doi:10.1186/1744-9081-3-2.

El-Sheikh, M., Cummings, E. M., \& Reiter, S. (1996). Preschoolers' responses to ongoing interadult conflict: The role of prior exposure to resolved versus unresolved arguments. Journal of Abnormal Child Psychology, 24(5), 665-679. Retrieved from http://search.proquest.com/docview/1300102272?accountid= 14772

Eme, R. (2013). MAOA and male antisocial behavior: A review. Aggression and Violent Behavior, 8(3), 395-398. doi:10.1016/j. avb.2013.02.001.

Enoch, M. A., Shen, P. H., Xu, K., Hodgkinson, C., \& Goldman, D. (2006). Using ancestry-informative markers to define populations and detect population stratification. Journal of Psychopharmacology, 20, 19-26. doi:10.1177/1359786806066041.

Eron, L. D. (1997). Spare the rod and spoil the child? Aggression and Violent Behavior, 2(4), 309-311. doi:10.1016/S13591789(97)00016-5.

Fanti, K. A., Panayiotou, G., Lazarou, C., Michael, R., \& Georgiou, G. (2015). The better of two evils? Evidence that children exhibiting continuous conduct problems high or low on callous-Unemotional traits score on opposite directions on physiological and behavioral measures of fear. Development and Psychopathology. Advance online publication. doi:10.1017/ S0954579415000371

Fergusson, D. M., Boden, J. M., Horwood, L. J., Miller, A. L., \& Kennedy, M. A. (2011). MAOA, abuse exposure and antisocial behaviour: 30-year longitudinal study. The British Journal of Psychiatry, 198, 457-463. doi:10.1192/bjp.bp.110.086991.

Fergusson, D. M., Boden, J. M., Horwood, L. J., Miller, A., \& Kennedy, M. A. (2012). Moderating role of the MAOA genotype in antisocial behaviour. The British Journal of Psychiatry, 200, 116-123. doi:10.1192/bjp.bp.111.093328.
Ficks, C. A., \& Waldman, I. D. (2014). Candidate genes for aggression and antisocial behavior: A meta-analysis of association studies of the 5HTTLPR and MAOA-uVNTR. Behavior Genetics, 44(5), 427-444. doi:10.1007/s10519-014-9661-y.

Finger, E. C., Marsh, A. A., Buzas, B., Kamel, N., Rhodes, R., Vythilingham, M., et al. (2006). The impact of tryptophan depletion and 5-HTTLPR genotype on passive avoidance and response reversal instrumental learning tasks. Neuropsychopharmacology, 32(1), 206-215. doi:10.1038/sj.npp.1301182.

Foley, D. L., Eaves, L. J., Wormley, B., Silberg, J. L., Maes, H. H., Kuhn, J., \& Riley, B. (2004). Childhood adversity, monoamine oxidase a genotype, and risk for conduct disorder. Archives of General Psychiatry, 61, 738-744. doi:10.1001/archpsyc.61.7. 738.

Fontaine, R. G. (2006). Evaluative behavioral judgments and instrumental antisocial behaviors in children and adolescents. Clinical Psychology Review, 26(8), 956-967. doi:10.1016/j.cpr. 2006.07.003.

Ford, B. Q., Mauss, I. B., Troy, A. S., Smolen, A., \& Hankin, B. (2014). Emotion regulation moderates the risk associated with the 5-HTT gene and stress in children. Emotion, 14(5), 930-939. doi:10.1037/a0036835.

Frazzetto, G., Di Lorenzo, G., Carola, V., Proietti, L., Sokolowska, E., Siracusano, A., et al. (2007). Early trauma and increased risk for physical aggression during adulthood: The moderating role of MAOA genotype. PLOS ONE, 2, e486. doi:10.1371/journal.pone. 0000486.

Frick, P. J. (2012). Developmental pathways to conduct disorder: Implications for future directions in research, assessment, and treatment. Journal of Clinical Child \& Adolescent Psychology, 41(3), 378-389. doi:10.1080/15374416.2012.664815.

Frick, P. J., \& Ellis, M. (1999). Callous-unemotional traits and subtypes of conduct disorder. Clinical Child and Family Psychology Review, 2(3), 149-168. doi:10.1023/A:1021803 005547.

Gallardo-Pujol, D., Andrés-Pueyo, A., \& Maydeu-Olivares, A. (2013). MAOA genotype, social exclusion and aggression: An experimental test of a gene-environment interaction. Genes, Brain and Behavior, 12(1), 140-145. doi:10.1111/j.1601-183X. 2012.00868.x.

Gao, Y., Raine, A., Venables, P. H., Dawson, M. E., \& Mednick, S. A. (2010a). Association of poor childhood fear conditioning and adult crime. American Journal of Psychiatry, 167, 56-60. doi:10. 1176/appi.ajp.2009.09040499.

Gao, Y., Raine, A., Venables, P. H., Dawson, M. E., \& Mednick, S. A. (2010b). Reduced electrodermal fear conditioning from ages 3 to 8 years is associated with aggressive behavior at age 8 years. Journal of Child Psychology and Psychiatry, 51(5), 550-558. doi:10.111/j.1469-7610.2009.02176.x.

Giesbrecht, G. F., Miller, M. R., \& Müller, U. (2010). The angerdistress model of temper tantrums: associations with emotional reactivity and emotional competence. Infant and Child Development, 19(5), 478-497. doi:10.1002/icd.677.

Glenn, A. L. (2011). The other allele: Exploring the long allele of the serotonin transporter gene as a potential risk factor for psychopathy: A review of the parallels in findings. Neuroscience and Biobehavioral Reviews, 35(3), 612-620. doi:10.1016/j. neubiorev.2010.07.005.

Goldman, D., Oroszi, G., \& Ducci, F. (2005). The genetics of addictions: Uncovering the genes. Nature Reviews Genetics, 6(7), 521-532. doi:10.1038/nrg1635.

Gratacòs, M., González, J. R., Mercader, J. M., de Cid, R., Urretavizcaya, M., \& Estivill, X. (2007). Brain-derived neurotrophic factor Val66Met and psychiatric disorders: Metaanalysis of case-control studies confirm association to substancerelated disorders, eating disorders, and schizophrenia. Biological 
Psychiatry, 61(7), 911-922. doi:10.1016/j.biopsych.2006.08. 025.

Greenberg, B. D., Tolliver, T. J., Huang, S. J., Li, Q., Bengel, D., \& Murphy, D. L. (1999). Genetic variation in the serotonin transporter promoter region affects serotonin uptake in human blood platelets. American Journal of Medical Genetics, 88(1), 83-87. doi:10.1002/(SICI)1096-8628(19990205)88:1<83:AIDAJMG15>3.0.CO;2-0.

Gregory, S., Blair, R. J., Simmons, A., Kumari, V., Hodgins, S., \& Blackwood, N. (2015). Punishment and psychopathy: A casecontrol functional MRI investigation of reinforcement learning in violent antisocial personality disordered men. The Lancet Psychiatry, 2(2), 153-160. doi:10.1016/S2215-0366(14)00071-6.

Griskevicius, V., Tybur, J. M., Delton, A. W., \& Robertson, T. E. (2011). The influence of mortality and socioeconomic status on risk and delayed rewards: A life history theory approach. Journal of Personality and Social Psychology, 100(6), 1015-1026. doi: $10.1037 / \mathrm{a} 0022403$.

Guyer, A. E., Kaufman, J., Hodgdon, H. B., Masten, C. L., Jazbec, S., Pine, D. S., \& Ernst, M. (2006). Behavioral alterations in reward system function: The role of childhood maltreatment and psychopathology. Journal of the American Academy of Child and Adolescent Psychiatry, 45(9), 1059-1067. doi:10.1097/01. chi.0000227882.50404.11.

Gyurak, A., Haase, C. M., Sze, J., Goodkind, M. S., Coppola, G., Lane, J., et al. (2013). The effect of the serotonin transporter polymorphism (5-HTTLPR) on empathic and self-conscious emotional reactivity. Emotion, 13(1), 25-35. doi:10.1037/ a0029616.

Haberstick, B. C., Lessem, J. M., Hopfer, C. J., Smolen, A., Ehringer, M. A., Timberlake, D., \& Hewitt, J. K. (2005). Monoamine oxidase A $(M A O A)$ and antisocial behaviors in the presence of childhood and adolescent maltreatment. American Journal of Medical Genetics Part B: Neuropsychiatric Genetics, 135B(1), 59-64. doi:10.1002/ajmg.b.30176.

Hankin, B. L., Nederhof, E., Oppenheimer, C. W., Jenness, J., Young, J. F., Abela, J. R. Z., et al. (2011). Differential susceptibility in youth: Evidence that 5-HTTLPR x positive parenting is associated with positive affect 'for better and worse'. Translational Psychiatry, 1(10), e44. doi:10.1038/tp.2011.44.

Hare, T. A., Tottenham, N., Galvan, A., Voss, H. U., Glover, G. H., \& Casey, B. (2008). Biological substrates of emotional reactivity and regulation in adolescence during an emotional go-nogo task. Biological Psychiatry, 63(10), 927-934. doi:10.1016/j.biopsych. 2008.03.015.

Hariri, A. R., \& Holmes, A. (2006). Genetics of emotional regulation: The role of the serotonin transporter in neural function. Trends in Cognitive Sciences, 10(4), 182-191. doi:10.1016/j.tics.2006.02. 011.

Hart, D., \& Marmorstein, N. R. (2009). Neighborhoods and genes and everything in between: Understanding adolescent aggression in social and biological contexts. Development and Psychopathology, 21, 961-973. doi:10.1017/S0954579409000510.

Heinz, A., Goldman, D., Jones, D. W., Palmour, R., Hommer, D., Gorey, J. G., et al. (2000). Genotype influences in vivo dopamine transporter availability in human striatum. Neuropsychopharmacology, 22(2), 133-139. doi:10.1016/S0893133X(99)00099-8.

Howe, G. W., Beach, S. R., \& Brody, G. H. (2010). Microtrial methods for translating gene-environment dynamics into preventive interventions. Prevention Science, 11(4), 343-354. doi:10.1007/s11121-010-0177-2.

Huizinga, D., Haberstick, B. C., Smolen, A., Menard, S., Young, S. E., Corley, R. P., et al. (2006). Childhood maltreatment, subsequent antisocial behavior, and the role of monoamine oxidase A genotype. Biological Psychiatry, 60, 677-683. doi:10. 1016/j.biopsych.2005.12.022.
Humphreys, K. L., \& Lee, S. S. (2011). Risk taking and sensitivity to punishment in children with ADHD, ODD, ADHD + ODD, and controls. Journal of Psychopathology and Behavioral Assessment, 33(3), 299-307. doi:10.1007/s10862-011-9237-6.

Isley, S. L., O’Neil, R., Clatfelter, D., \& Parke, R. D. (1999). Parent and child expressed affect and children's social competence: Modeling direct and indirect pathways. Developmental Psychology, 35(2), 547-560. doi:10.1037/0012-1649.35.2.547.

Jacobson, K. C., \& Crockett, L. J. (2000). Parental monitoring and adolescent adjustment: An ecological perspective. Journal of Research on Adolescence, 10(1), 65-97. doi:10.1207/ SJRA1001_4.

Jaffee, S. R., Price, T. S., \& Reyes, T. M. (2013). Behavior genetics: Past, present, future. Development and Psychopathology, 25, 1225-1242. doi:10.1017/S0954579413000588.

Jokela, M., Ferrie, J., \& Kivimäki, M. (2009). Childhood problem behaviors and death by midlife: the British National Child Development Study. Journal of the American Academy of Child and Adolescent Psychiatry, 48(1), 19-24. doi:10.1097/CHI. 0b013e31818b1c76.

Keller, M. C. (2014). Gene $\times$ environment interaction studies have not properly controlled for potential confounders: The problem and the (simple) solution. Biological Psychiatry, 75, 18-24. doi:10.1016/j.biopsych.2013.09.006.

Kilford, E. J., Dumontheil, I., Wood, N. W., \& Blakemore, S. J. (2015). Influence of COMT genotype and affective distractors on the processing of self-generated thought. Social Cognitive and Affective Neuroscience, 10(6), 777-782. doi:10.1093/scan/ nsu118.

Kim-Cohen, J., Caspi, A., Taylor, A., Williams, B., Newcombe, R., Craig, I. W., \& Moffitt, T. E. (2006). MAOA, maltreatment, and gene-environment interaction predicting children's mental health: New evidence and a meta-analysis. Molecular Psychiatry, 11(10), 903-913. doi:10.1038/sj.mp.4001851.

Kinnally, E. L., Huang, Y., Haverly, R., Burke, A. K., Galfalvy, H., Brent, D. P., et al. (2009). Parental care moderates the influence of MAOA-uVNTR genotype and childhood stressors on trait impulsivity and aggression in adult women. Psychiatric Genetics, 19, 126-133. doi:10.1097/YPG.0b013e32832a50a7.

Kobayashi, S., \& Schultz, W. (2008). Influence of reward delays on responses of dopamine neurons. The Journal of Neuroscience, 28(31), 7837-7846. doi:10.1523/JNEUROSCI.1600-08.2008.

Kobiella, A., Reimold, M., Ulshöfer, D., Ikonomidou, V., Vollmert, C., Vollstädt-Klein, S., et al. (2011). How the serotonin transporter 5-HTTLPR polymorphism influences amygdala function: The roles of in vivo serotonin transporter expression and amygdala structure. Translational Psychiatry, 1(8), e37. doi:10.1038/tp.2011.29.

Kochanska, G. (1997). Multiple pathways to conscience for children with different temperaments: From toddlerhood to age 5 . Developmental Psychology, 33, 228-240. doi:10.1037//00121649.33.2.228.

Kochanska, G., Aksan, N., \& Joy, M. E. (2007). Children's fearfulness as a moderator of parenting in early socialization: Two longitudinal studies. Developmental Psychology, 43(1), 222-237. doi:10.1037/0012-1649.43.1.222.

Lancaster, T. M., Linden, D. E., \& Heerey, E. A. (2012). COMT val158met predicts reward responsiveness in humans. Genes, Brain and Behavior, 11(8), 986-992. doi:10.1111/j.1601-183X. 2012.00838.x.

Lavigne, J. V., Herzing, L. B., Cook, E. H., LeBailly, S. A., Gouze, K. R., Hopkins, J., \& Bryant, F. B. (2013). Gene $\times$ environment effects of serotonin transporter, dopamine receptor D4, and monoamine oxidase A genes with contextual and parenting risk factors on symptoms of oppositional defiant disorder, anxiety, and depression in a community sample of 4-year-old children. 
Development and Psychopathology, 25, 555-575. doi:10.1017/ S0954579412001241.

Lesch, K., Bengel, D., Heils, A., Sabol, S. Z., Greenberg, B. D., Petri, S., et al. (1996). Association of anxiety-related traits with a polymorphism in the serotonin transporter gene regulatory region. Science, 274(5292), 1527-1531. doi:10.1126/science. 274.5292.1527.

Li, J. J., \& Lee, S. S. (2010). Latent class analysis of antisocial behavior: Interaction of serotonin transporter genotype and maltreatment. Journal of Abnormal Child Psychology, 38, 789-801. doi:10.1007/s10802-010-9409-y.

Li, T., Xu, K., Deng, H., Cai, G., Liu, J., Liu, X., et al. (1997). Association analysis of the dopamine D4 gene exon III VNTR and heroin abuse in Chinese subjects. Molecular Psychiatry, 2(5), 413-416. doi:10.1038/sj.mp.400031.

Lim, L., Radua, J., \& Rubia, K. (2014). Gray matter abnormalities in childhood maltreatment: A voxel-wise meta-analysis. American Journal of Psychiatry, 171(8), 854-863. doi:10.1176/appi.ajp. 2014.13101427.

Loo, S. K., Lenartowicz, A., \& Makeig, S. (2015). Research review: Use of EEG biomarkers in child psychiatry research-current state and future directions. Journal of Child Psychology and Psychiatry. Advance online publication. doi:10.1111/jcpp.12435

Lotta, T., Vidgren, J., Tilgmann, C., Ulmanen, I., Melen, K., Julkunen, I., \& Taskinen, J. (1995). Kinetics of human soluble and membrane-bound catechol $O$-methyltransferase: A revised mechanism and description of the thermolabile variant of the enzyme. Biochemistry, 34(13), 4202-4210. doi:10.1021/bi00013a008.

Lykken, D. T. (1957). A study of anxiety in the sociopathic personality. The Journal of Abnormal and Social Psychology, 55(1), 6-10. doi:10.1037/h0047232.

Manica, A., Prugnolle, F., \& Balloux, F. (2005). Geography is a better determinant of human genetic differentiation than ethnicity. Human Genetics, 118(3-4), 366-371. doi:10.1007/s00439-0050039-3.

Marsman, R., Oldehinkel, A. J., Ormel, J., \& Buitelaar, J. K. (2013). The dopamine receptor D4 gene and familial loading interact with perceived parenting in predicting externalizing behavior problems in early adolescence: The TRacking adolescents' individual lives survey (TRAILS). Psychiatry Research, 209(1), 66-73. doi:10.1016/j.psychres.2012.10.022.

Martel, M. M., Nikolas, M., Jernigan, K., Friderici, K., Waldman, I., \& Nigg, J. T. (2011). The dopamine receptor D4 gene (DRD4) moderates family environmental effects on ADHD. Journal of Abnormal Child Psychology, 39(1), 1-10. doi:10.1007/s10802010-9439-5.

Massar, S. A., Kenemans, J. L., \& Schutter, D. J. (2014). Resting-state EEG theta activity and risk learning: Sensitivity to reward or punishment? International Journal of Psychophysiology, 91(3), 172-177. doi:10.1016/j.ijpsycho.2013.10.013.

Masten, A. S. (2007). Resilience in developing systems: Progress and promise as the fourth wave rises. Development and Psychopathology, 19(3), 921-930. doi:10.1017/S0954579407000442.

Matthys, W., Van Goozen, S. H., Snoek, H., \& Van Engeland, H. (2004). Response perseveration and sensitivity to reward and punishment in boys with oppositional defiant disorder. European Child and Adolescent Psychiatry, 13(6), 362-364. doi:10.1007/ s00787-004-0395-x.

Matthys, W., Vanderschuren, L., \& Schutter, D. (2013). The neurobiology of oppositional defiant disorder and conduct disorder: Altered functioning in three mental domains. Development and Psychopathology, 1(1), 1-15. doi:10.1017/ S0954579412000272.

Matthys, W., Vanderschuren, L. J., Schutter, D. J., \& Lochman, J. E. (2012). Impaired neurocognitive functions affect social learning processes in oppositional defiant disorder and conduct disorder:
Implications for interventions. Clinical Child and Family Psychology Review, 15(3), 234-246. doi:10.1007/s10567-0120118-7.

McGrath, L., Mustanski, B., Metzger, A., Pine, D., Kistner-Griffin, E., Cook, E., \& Wakschlag, L. (2012). A latent modeling approach to genotype-phenotype relationships: Maternal problem behavior clusters, prenatal smoking, and MAOA genotype. Archives of Women's Mental Health, 15, 269-282. doi:10.1007/s00737-0120286-y.

Melzack, R., \& Scott, T. (1957). The effects of early experience on the response to pain. Journal of Comparative and Physiological Psychology, 50(2), 155-161. doi:10.1037/h0047770.

Meyer, B. M., Huemer, J., Rabl, U., Boubela, R. N., Kalcher, K., Berger, A., et al. (2014). Oppositional COMT Val158Met effects on resting state functional connectivity in adolescents and adults. Brain Structure and Function,. doi:10.1007/s00429-014-0895-5.

Miczek, K. A., Fish, E. W., Joseph, F., \& De Almeida, R. M. (2002). Social and neural determinants of aggressive behavior: Pharmacotherapeutic targets at serotonin, dopamine and $\gamma$-aminobutyric acid systems. Psychopharmacology (Berl), 163(3-4), 434-458. doi:10.1007/s00213-002-1139-6.

Mier, D., Kirsch, P., \& Meyer-Lindenberg, A. (2009). Neural substrates of pleiotropic action of genetic variation in COMT: A meta-analysis. Molecular Psychiatry, 15(9), 918-927. doi:10. 1038/mp.2009.36.

Miner, J. L., \& Clarke-Stewart, K. A. (2008). Trajectories of externalizing behavior from age 2 to age 9: Relations with gender, temperament, ethnicity, parenting, and rater. Developmental Psychology, 44(3), 771-786. doi:10.1037/0012-1649.44. 3.771 .

Missale, C., Nash, S. R., Robinson, S. W., Jaber, M., \& Caron, M. G. (1998). Dopamine receptors: From structure to function. Physiological Reviews, 78(1), 189-225. Retrieved from: http:// physrev.physiology.org/content/78/1/189.short

Moffitt, T. E., Caspi, A., \& Rutter, M. (2006). Measured geneenvironment interactions in psychopathology concepts, research strategies, and implications for research, intervention, and public understanding of genetics. Perspectives on Psychological Science, 1(1), 5-27. doi:10.1111/j.1745-6916.2006.00002.x.

Morgan-Lopez, A. A., \& MacKinnon, D. P. (2006). Demonstration and evaluation of a method for assessing mediated moderation. Behavior Research Methods, 38(1), 77-87. doi:10.3758/ BF03192752.

Muller, D., Judd, C. M., \& Yzerbyt, V. Y. (2005). When moderation is mediated and mediation is moderated. Journal of Personality and Social Psychology, 89(6), 852-863. doi:10.1037/0022-3514. 89.6.852.

Munafò, M., Bowes, L., Clark, T., \& Flint, J. (2005). Lack of association of the COMT (Val158/108 met) gene and schizophrenia: A meta-analysis of case-control studies. Molecular Psychiatry, 10(8), 765-770. doi:10.1016/j.biopsych.2007.08.016.

Munafò, M. R., Brown, S. M., \& Hariri, A. R. (2008). Serotonin transporter $(5-H T T L P R)$ genotype and amygdala activation: A meta-analysis. Biological Psychiatry, 63(9), 852-857. doi:10. 1016/j.biopsych.2007.08.016.

Murphy, S. E., Norbury, R., Godlewska, B. R., Cowen, P. J., Mannie, Z. M., Harmer, C. J., \& Munafò, M. R. (2013). The effect of the serotonin transporter polymorphism (5-HTTLPR) on amygdala function: A meta-analysis. Molecular psychiatry, 18(4), 512-520. doi:10.1038/mp.2012.19.

Naylor, L., Dean, B., Pereira, A., Mackinnon, A., Kouzmenko, A., \& Copolov, D. (1998). No association between the serotonin transporter-linked promoter region polymorphism and either schizophrenia or density of the serotonin transporter in human hippocampus. Molecular Medicine, 4(10), 671-674. Retrieved from http://www.ncbi.nlm.nih.gov/pmc/articles/PMC2230253/ 
Neale, B. M., Medland, S. E., Ripke, S., Asherson, P., Franke, B., Lesch, K. P., et al. (2010). Meta-analysis of genome-wide association studies of attention-deficit/hyperactivity disorder. Journal of the American Academy of Child and Adolescent Psychiatry, 49(9), 884-897. doi:10.1016/j.jaac.2010.06.008.

Nederhof, E., Belsky, J., Ormel, J., \& Oldehinkel, A. J. (2012). Effects of divorce on Dutch boys' and girls' externalizing behavior in gene $\times$ environment perspective: Diathesis stress or differential susceptibility in the Dutch tracking adolescents' individual lives survey study? Development and Psychopathology, 24(03), 929-939. doi:10.1017/S0954579412000454.

Neville, M. J., Johnstone, E. C., \& Walton, R. T. (2004). Identification and characterization of ANKK1: A novel kinase gene closely linked to DRD2 on chromosome band 11q23. 1. Human Mutation, 23(6), 540-545. doi:10.1002/humu.20039.

Nikitopoulos, J., Zohsel, K., Blomeyer, D., Buchmann, A. F., Schmid, B., Jennen-Steinmetz, C., et al. (2014). Are infants differentially sensitive to parenting? Early maternal care, DRD4 genotype and externalizing behavior during adolescence. Journal of Psychiatric Research, 59, 53-59. doi:10.1016/j.jpsychires.2014.08.012.

Nilsson, K. W., Sjöberg, R. L., Damberg, M., Leppert, J., Öhrvik, J., Alm, P. O., et al. (2006). Role of monoamine oxidase A genotype and psychosocial factors in male adolescent criminal activity. Biological Psychiatry, 59, 121-127. doi:10.1016/j. biopsych.2005.06.024.

Nissen, H. W., Chow, K. L., \& Semmes, J. (1951). Effects of restricted opportunity for actual, kinesthetic, and manipulative experience on the behavior of a chimpanzee. The American Journal of Psychology, 64(4), 485-507. Retrieved from http:// www.jstor.org/stable/1418189

Nobile, M., Giorda, R., Marino, C., Carlet, O., Pastore, V., Vanzin, L., et al. (2007). Socioeconomic status mediates the genetic contribution of the dopamine receptor D4 and serotonin transporter linked promoter region repeat polymorphisms to externalization in preadolescence. Development and Psychopathology, 19, 1147-1160. doi:10.1017/S0954579407000594.

Nobile, M., Rusconi, M., Bellina, M., Marino, C., Giorda, R., Carlet, O., et al. (2010). COMT Val158Met polymorphism and socioeconomic status interact to predict attention deficit/hyperactivity problems in children aged 10-14. European Child and Adolescent Psychiatry, 19, 549-557. doi:10.1017/S0954579407000594.

Noble, E. P., Blum, K., Ritchie, T., Montgomery, A., \& Sheridan, P. J. (1991). Allelic association of the D2 dopamine receptor gene with receptor-binding characteristics in alcoholism or geneism. Archives of General Psychiatry, 48(7), 648-654. doi:10.1001/ archpsyc.1991.01810310066012.

Nordquist, N., \& Oreland, L. (2010). Serotonin, genetic variability, behaviour, and psychiatric disorders-A review. Upsala Journal of Medical Sciences, 115(1), 2-10. doi:10.1007/s10519-010-9356-y.

Ou, X. M., Chen, K., \& Shih, J. C. (2006). Glucocorticoid and androgen activation of monoamine oxidase $\mathrm{A}$ is regulated differently by R1 and Sp1. Journal of Biological Chemistry, 281(30), 21512-21525. doi:10.1074/jbc.M600250200.

Overbeek, G., Weeland, J., \& Chhangur, R. (2012). Commentary research on gene-environment interdependence: Honing the tools and examining the angles. European Journal of Developmental Psychology, 9(4), 413-418. doi:10.1080/17405629.2012. 690603.

Pappa, I., Fedko, I. O., Mileva-Seitz, V. R., Hottenga, J. J., Bakermans-Kranenburg, M. J., Bartels, M., et al. (2015). Single nucleotide polymorphism heritability of behavior problems in childhood: Genome-wide complex trait analysis. Journal of the American Academy of Child and Adolescent Psychiatry, 54, 737-744. doi:10.1016/j.jaac.2015.06.004.

Pessiglione, M., Seymour, B., Flandin, G., Dolan, R. J., \& Frith, C. D. (2006). Dopamine-dependent prediction errors underpin reward- seeking behaviour in humans. Nature, 442(7106), 1042-1045. doi:10.1038/nature05051.

Pezawas, L., Meyer-Lindenberg, A., Drabant, E. M., Verchinski, B. A., Munoz, K. E., Kolachana, B. S., et al. (2005). 5-HTTLPR polymorphism impacts human cingulate-amygdala interactions: A genetic susceptibility mechanism for depression. Nature Neuroscience, 8(6), 828-834. doi:10.1038/nn1463.

Pfeifer, J. H., Iacoboni, M., Mazziotta, J. C., \& Dapretto, M. (2008). Mirroring others' emotions relates to empathy and interpersonal competence in children. NeuroImage, 39(4), 2076-2085. doi:10. 1016/j.neuroimage.2007.10.032.

Pinsonneault, J. K., Papp, A. C., \& Sadée, W. (2006). Allelic mRNA expression of $\mathrm{X}$-linked monoamine oxidase a $(M A O A)$ in human brain: dissection of epigenetic and genetic factors. Human Molecular Genetetics, 15(17), 2636-2649. doi:10.1093/hmg/ dd1192.

Plomin, R., \& Simpson, M. A. (2013). The future of genomics for developmentalists. Development and Psychopathology, 25(4pt2), 1263-1278. doi:10.1017/S0954579413000606.

Pluess, M., \& Belsky, J. (2013). Vantage sensitivity: Individual differences in response to positive experiences. Psychological Bulletin, 139, 901-916. doi:10.1037/a0030196.

Prichard, Z., Mackinnon, A., Jorm, A. F., \& Easteal, S. (2008). No evidence for interaction between MAOA and childhood adversity for antisocial behavior. American Journal of Medical Genetics Part B: Neuropsychiatric Genetics, 147B, 228-232. doi:10.1002/ ajmg.b.30581.

Prom-Wormley, E. C., Eaves, L. J., Foley, D. L., Gardner, C. O., Archer, K. J., Wormley, B. K., et al. (2009). Monoamine oxidase A and childhood adversity as risk factors for conduct disorder in females. Psychological Medicine, 39, 579-590. doi:10.1017/ S0033291708004170.

Propper, C., Willoughby, M., Halpern, C. T., Carbone, M. A., \& Cox, M. (2007). Parenting quality, DRD4, and the prediction of externalizing and internalizing behaviors in early childhood. Developmental Psychobiology, 49, 619-632. doi:10.1002/dev.20249.

Pryce, C. R., Dettling, A. C., Spengler, M., Schnell, C. R., \& Feldon, J. (2004). Deprivation of parenting disrupts development of homeostatic and reward systems in marmoset monkey offspring. Biological Psychiatry, 56(2), 72-79. doi:10.1016/j.biopsych. 2004.05.00.

Quay, H. C. (1988). The behavioral reward and inhibition system in childhood behavior disorder. In L. M. Bloomingdale (Ed.), Attention deficit disorder (Vol. 3, pp. 176-186)., New research in attention, treatment, and psychopharmacology Elmsford, NY: Pergamon Press.

Reif, A., Rösler, M., Freitag, C. M., Schneider, M., Eujen, A., Kissling, C., et al. (2007). Nature and nurture predispose to violent behavior: Serotonergic genes and adverse childhood environment. Neuropsychopharmacology, 32, 2375-2383. doi:10.1038/sj.npp.1301359.

Reiss, D., \& Leve, L. D. (2007). Genetic expression outside the skin: Clues to mechanisms of genotype $\times$ environment interaction. Development and Psychopathology, 19(04), 1005-1027. doi:10. 1017/S0954579407000508.

Reiss, D., Leve, L. D., \& Neiderhiser, J. M. (2013). How genes and the social environment moderate each other. American Journal of Public Health, 103(S1), S111-S121. doi:10.2105/AJPH.2013. 301408.

Reti, I. M., Xu, J. Z., Yanofski, J., McKibben, J., Uhart, M., Cheng, Y., et al. (2011). Monoamine oxidase A regulates antisocial personality in whites with no history of physical abuse. Comprehensive Psychiatry, 52, 188-194. doi:10.1016/j.compp sych.2010.05.005.

Richards, J. S., Hartman, C. A., Franke, B., Hoekstra, P. J., Heslenfeld, D. J., Oosterlaan, J., et al. (2015). Differential 
susceptibility to maternal expressed emotion in children with ADHD and their siblings? Investigating plasticity genes, prosocial and antisocial behaviour. European Child and Adolescent Psychiatry, 24, 209-217. doi:10.1007/s00787-014-0567-2.

Robinson, T. E., \& Berridge, K. C. (2008). The incentive sensitization theory of addiction: Some current issues. Philosophical Transactions of the Royal Society B: Biological Sciences, 363(1507), 3137-3146. doi:10.1098/rstb.2008.0093.

Roth, T. L. (2013). Epigenetic mechanisms in the development of behavior: Advances, challenges, and future promises of a new field. Development and Psychopathology, 25, 1279-1291. doi:10.1017/S0954579413000618.

Rothbart, M. K., \& Derryberry, D. (1981). Development of individual differences in temperament. In M. E. Lamb \& A. Brown (Eds.), Advances in developmental psychology (Vol. 1, pp. 37-86). Hillsdale, NJ: Erlbaum.

Rutter, M. (2007). Gene-environment interdependence. Developmental Science, 10(1), 12-18. doi:10.1111/j.1467-7687.2007.00557.x.

Rutter, M. (2012). Gene-environment interdependence. European Journal of Developmental Psychology, 9(4), 391-412. doi:10. 1080/17405629.2012.661174.

Rutter, M., Moffitt, T. E., \& Caspi, A. (2006). Gene-environment interplay and psychopathology: Multiple varieties but real effects. Journal of Child Psychology and Psychiatry, 47(3-4), 226-261. doi:10.1111/j.1469-7610.2005.01557.x.

Sabol, S. Z., Hu, S., \& Hamer, D. (1998). A functional polymorphism in the monoamine oxidase A gene promoter. Human Genetics, 103(3), 273-279. doi:10.1007/s004390050816.

Sadeh, N., Javdani, S., Jackson, J. J., Reynolds, E. K., Potenza, M. N., Gelernter, J., et al. (2010). Serotonin transporter gene associations with psychopathic traits in youth vary as a function of socioeconomic resources. Journal of Abnormal Psychology, 119(3), 604-609. doi:10.1037/a0019709.

Sadeh, N., Javdani, S., \& Verona, E. (2013). Analysis of monoaminergic genes, childhood abuse, and dimensions of psychopathy. Journal of Abnormal Psychology, 122, 167-179. doi:10.1037/ a0029866167.

Salvatore, J. E., Aliev, F., Bucholz, K., Agrawal, A., Hesselbrock, V., Hesselbrock, M., et al. (2014). Polygenic risk for externalizing disorders: Gene-by-development and gene-by-environment effects in adolescents and young adults. Clinical Psychological Science, 3, 189-201. doi:10.1177/2167702614534211.

Salvatore, J. E., \& Dick, D. M. (2015). Gene-environment interplay: Where we are, where we are going. Journal of Marriage and Family, 77(2), 344-350. doi:10.1111/jomf.12164.

Santesso, D. L., Dzyundzyak, A., \& Segalowitz, S. J. (2011). Age, sex and individual differences in punishment sensitivity: Factors influencing the feedback-related negativity. Psychophysiology, 48(11), 1481-1489. doi:10.1111/j.1469-8986.2011.01229.x.

Schlomer, G. L., Cleveland, H. H., Vandenbergh, D. J., Feinberg, M. E., Neiderhiser, J. M., Greenberg, M. T., et al. (2015). Developmental differences in early adolescent aggression: A gene $\times$ environment $\times$ intervention analysis. Journal of Youth and Adolescence, 44, 581-597. doi:10.1007/s10964-014-0198-4.

Schmidt, L., Sander, T., Kuhn, S., Smolka, M., Rommelspacher, H., Samochowiec, J., \& Lesch, K. (2000). Different allele distribution of a regulatory MAOA gene promoter polymorphism in antisocial and anxious-depressive alcoholics. Journal of Neural Transmission, 107(6), 681-689. doi:10.1007/s007020070069.

Schoots, O., \& Van Tol, H. (2003). The human dopamine D4 receptor repeat sequences modulate expression. The Pharmacogenomics Journal, 3(6), 343-348. doi:10.1038/sj.tpj.6500208.

Schultz, W. (2010). Review dopamine signals for reward value and risk: Basic and recent data. Behavioral and Brain Functions, 6(24), e24. doi:10.1186/1744-9081-6-24.
Scott, S., \& O'Connor, T. G. (2012). An experimental test of differential susceptibility to parenting among emotionally-dysregulated children in a randomized controlled trial for oppositional behavior. Journal of Child Psychology and Psychiatry, 53(11), 1184-1193. doi:10.111/j.1469-7610.2012.02586.x.

Sevy, S., Hassoun, Y., Bechara, A., Yechiam, E., Napolitano, B., Burdick, K., et al. (2006). Emotion-based decision-making in healthy subjects: Short-term effects of reducing dopamine levels. Psychopharmacology (Berl), 188(2), 228-235. doi:10.1007/ s00213-006-0450-z.

Sheese, B. E., Voelker, P., Posner, M. I., \& Rothbart, M. K. (2009). Genetic variation influences on the early development of reactive emotions and their regulation by attention. Cognitive Neuropsychiatry, 14(4-5), 332-355. doi:10.1080/13546800902844064.

Simmons, J. P., Nelson, L. D., \& Simonsohn, U. (2011). Falsepositive psychology undisclosed flexibility in data collection and analysis allows presenting anything as significant. Psychological Science, 22(11), 1359-1366. doi:10.1177/0956797611417632.

Simons, R. L., Lei, M. K., Beach, S. R., Brody, G. H., Philibert, R. A., \& Gibbons, F. X. (2011). Social environment, genes, and aggression evidence supporting the differential susceptibility perspective. American Sociological Review, 76, 883-912. doi:10.1177/0003122411427580.

Sjöberg, R. L., Nilsson, K. W., Wargelius, H., Leppert, J., Lindström, L., \& Oreland, L. (2007). Adolescent girls and criminal activity: Role of MAOA-LPR genotype and psychosocial factors. American Journal of Medical Genetics Part B: Neuropsychiatric Genetics, 144B, 159-164. doi:10.1002/ajmg.b.30360.

Sonuga-Barke, E. J., Oades, R. D., Psychogiou, L., Chen, W., Franke, B., Buitelaar, J., et al. (2009). Dopamine and serotonin transporter genotypes moderate sensitivity to maternal expressed emotion: The case of conduct and emotional problems in attention deficit/ hyperactivity disorder. Journal of Child Psychology and Psychiatry, 50, 1052-1063. doi:10.1111/j.1469-7610.2009.02095.x.

Steinberg, L. (2007). Risk taking in adolescence new perspectives from brain and behavioral science. Current Directions in Psychological Science, 16(2), 55-59. doi:10.1111/j.1467-8721. 2007.00475.x.

Stephens, S. H., Hoft, N. R., Schlaepfer, I. R., Young, S. E., Corley, R. C., McQueen, M. B., et al. (2012). Externalizing behaviors are associated with SNPs in the CHRNA5/CHRNA3/CHRNB4 gene cluster. Behavior Genetics, 42(3), 402-414. doi:10.1007/s10519011-9514-x.

Sterzer, P., Stadler, C., Krebs, A., Kleinschmidt, A., \& Poustka, F. (2005). Abnormal neural responses to emotional visual stimuli in adolescents with conduct disorder. Biological Psychiatry, 57(1), 7-15. doi:10.1016/j.biopsych.2004.10.008.

Stice, E., Yokum, S., Burger, K., Epstein, L., \& Smolen, A. (2012). Multilocus genetic composite reflecting dopamine signaling capacity predicts reward circuitry responsivity. The Journal of Neuroscience, 32(29), 10093-10100. doi:10.1523/JNEUROSCI. 1506-12.2012.

Stringaris, A., Zavos, H., Leibenluft, E., Maughan, B., \& Eley, T. (2012). Adolescent irritability: Phenotypic associations and genetic links with depressed mood. The American Journal of Psychiatry, 169(1), 47-54. doi:10.1176/appi.ajp.2011.10101549.

Szyf, M., \& Bick, J. (2013). DNA methylation: A mechanism for embedding early life experiences in the genome. Child Development, 84(1), 49-57. doi:10.1111/j.1467-8624.2012.01793.x.

Taylor, A., \& Kim-Cohen, J. (2007). Meta-analysis of geneenvironment interactions in developmental psychopathology. Development and Psychopathology, 19(4), 1029-1037. doi:10. 1017/S095457940700051X.

Thompson, J., Sonuga-Barke, E. J., Morgan, A. R., Cornforth, C. M., Turic, D., Ferguson, L. R., et al. (2012). The catechol- $O$ - 
methyltransferase (COMT) Val158Met polymorphism moderates the effect of antenatal stress on childhood behavioural problems: Longitudinal evidence across multiple ages. Developmental Medicine and Child Neurology, 54(2), 148-154. doi:10.1111/j.1469-8749.2011.04129.x.

Tolan, P. H., Dodge, K., \& Rutter, M. (2013). Tracking the multiple pathways of parent and family influence on disruptive behavior disorders. In P. H. Tolan \& B. L. Leventhal (Eds.), Disruptive behavior disorders (pp. 161-191). New York: Springer.

Treadway, M. T., Buckholtz, J. W., Martin, J. W., Jan, K., Asplund, C. L., Ginther, M. R., et al. (2014). Corticolimbic gating of emotion-driven punishment. Nature Neuroscience, 17(9), 1270-1275. doi:10.1038/nn.3781.

Uher, R., \& McGuffin, P. (2007). The moderation by the serotonin transporter gene of environmental adversity in the aetiology of mental illness: Review and methodological analysis. Molecular Psychiatry, 13(2), 131-146. doi:10.1038/sj.mp.4002067.

Van der Vegt, E. J. M., Oostra, B. A., Arias-Vásquez, A., Van der Ende, J., Verhulst, F., \& Tiemeier, H. (2009). High activity of monoamine oxidase $\mathrm{A}$ is associated with externalizing behaviour in maltreated and non-maltreated adoptees. Psychiatric Genetics, 19, 209-211. doi:10.1097/YPG.0b013e32832a5084.

Van Dyck, C. H., Malison, R. T., Jacobsen, L. K., Seibyl, J. P., Staley, J. K., Laruelle, M., et al. (2005). Increased dopamine transporter availability associated with the 9-repeat allele of the SLC6A3 gene. The Journal of Nuclear Medicine, 46(5), 745-751. Retrieved from: http://jnm.snmjournals.org/content/46/5/745.short

Van IJzendoorn, M. H., \& Bakermans-Kranenburg, M. J. (2015). Genetic differential susceptibility on trial: Meta-analytic support from randomized controlled experiments. Development and Psychopathology, 27(01), 151-162. doi:10.1017/S0954579414001369.

Van IJzendoorn, M. H., Bakermans-Kranenburg, M. J., \& Ebstein, R. P. (2011). Methylation matters in child development: Toward developmental behavioral epigenetics. Child Development Perspectives, 5(4), 305-310. doi:10.1111/j.1750-8606.2011.00202.x.

Van IJzendoorn, M. H., Belsky, J., \& Bakermans-Kranenburg, M. J. (2012). Serotonin transporter genotype 5HTTLPR as a marker of differential susceptibility? A meta-analysis of child and adolescent gene-by-environment studies. Translational Psychiatry, 2(8), e147. doi:10.1038/tp.2012.73.

Van Tol, H. H., Wu, C. M., Guan, H., Ohara, K., Bunzow, J. R., Civelli, O., et al. (1992). Multiple dopamine D4 receptor variants in the human population. Nature, 358, 149-152. doi:10.1038/ $358149 \mathrm{a} 0$.

VanNess, S. H., Owens, M. J., \& Kilts, C. D. (2005). The variable number of tandem repeats element in DAT1 regulates in vitro dopamine transporter density. BMC Genetics, $6(\mathrm{e} 1), 55$. doi:10. 1186/1471-2156-6-55

Vanyukov, M. M., Maher, B. S., Devlin, B., Kirillova, G. P., Kirisci, L., Yu, L., \& Ferrell, R. E. (2007). The MAOA promoter polymorphism, disruptive behavior disorders, and early onset substance use disorder: Gene-environment interaction. Psychiatric Genetics, 17, 323-332. doi:10.1097/YPG.0b013e32811f6691.

Volkow, N., Wang, G., Fischman, M., Foltin, R., Fowler, J., Abumrad, N., et al. (1997). Relationship between subjective effects of cocaine and dopamine transporter occupancy. Nature, 386, 827-830. doi:10.1038/386827a0.

Von Stumm, S., Deary, I. J., Kivimäki, M., Jokela, M., Clark, H., \& Batty, G. D. (2011). Childhood behavior problems and health at midlife: 35-year follow-up of a Scottish birth cohort. Journal of Child Psychology and Psychiatry and Allied Disciplines, 52(9), 992-1001. doi:10.1111/j.1469-7610.2011.02373.x.
Wagner, S., Baskaya, Ö., Anicker, N. J., Dahmen, N., Lieb, K., \& Tadić, A. (2010). The catechol o-methyltransferase (COMT) val158met polymorphism modulates the association of serious life events (SLE) and impulsive aggression in female patients with borderline personality disorder (BPD). Acta Psychiatrica Scandinavica, 122(2), 110-117. doi:10.1111/j.1600-0447.2009. 01501.x.

Walsh, N. D., Dalgleish, T., Dunn, V. J., Abbott, R., St Clair, M. C., Owens, M., et al. (2012). 5-HTTLPR-environment interplay and its effects on neural reactivity in adolescents. NeuroImage, 24(2), 665-680. doi:10.1016/j.neuroimage.2012.07.067.

Webb, J. A., Bray, J. H., Getz, J. G., \& Adams, G. (2002). Gender, perceived parental monitoring, and behavioral adjustment: Influences on adolescent alcohol use. American Journal of Orthopsychiatry, 72(3), 392-400. doi:10.1037/0002-9432.72.3.392.

Weder, N., Yang, B. Z., Douglas-Palumberi, H., Massey, J., Krystal, J. H., Gelernter, J., \& Kaufman, J. (2009). MAOA genotype, maltreatment, and aggressive behavior: The changing impact of genotype at varying levels of trauma. Biological Psychiatry, 65, 417-424. doi:10.1016/j.biopsych.2008.09.013.

Weeland, J., Slagt, M. I., Brummelman, E., Matthys, W., Orobio de Castro, B., \& Overbeek, G. (2015). 5-HTTLPR Expression outside the skin: An experimental test of the emotional reactivity hypothesis in Children. PloS one. doi:10.1371/journal.pone. 0141474.

Widom, C. S., \& Brzustowicz, L. M. (2006). MAOA and the "Cycle of violence:" Childhood abuse and neglect, MAOA genotype, and risk for violent and antisocial behavior. Biological Psychiatry, 60, 684-689. doi:10.1016/j.biopsych.2006.03.039.

Williams, R. B., Surwit, R. S., Siegler, I. C., Ashley-Koch, A. E., Collins, A. L., Helms, M. J., et al. (2010). Central nervous system serotonin and clustering of hostility, psychosocial, metabolic and cardiovascular endophenotypes in men. Psychosomatic Medicine, 72(7), 601-607. doi:10.1097/PSY.0b013e3 $181 \mathrm{eb} 9 \mathrm{~d} 67$.

Windhorst, D. A., Mileva-Seitz, V. R., Linting, M., Hofman, A., Jaddoe, V. W., Verhulst, F. C., et al. (2015). Differential susceptibility in a developmental perspective: DRD4 and maternal sensitivity predicting externalizing behavior. Developmental Psychobiology, 57(1), 35-49. doi:10.1002/dev.21257.

Wishart, H. A., Roth, R. M., Saykin, A. J., Rhodes, C. H., Tsongalis, G. J., Pattin, K. A., et al. (2011). COMT Val158Met genotype and individual differences in executive function in healthy adults. Journal of the International Neuropsychological Society, 17(01), 174-180. doi:10.1017/S1355617710001402.

Yang, B., Chan, R. C. K., Jing, J., Li, T., Sham, P., \& Chen, R. Y. L. (2007). A meta-analysis of association studies between the 10-repeat allele of a VNTR polymorphism in the 3?-UTR of dopamine transporter gene and attention deficit hyperactivity disorder. American Journal of Medical Genetics Part B: Neuropsychiatric Genetics, 144B(4), 541-550. doi:10.1002/ ajmg.b.30453.

Yildirim, B. O., \& Derksen, J. J. L. (2013). Systematic review, structural analysis, and new theoretical perspectives on the role of serotonin and associated genes in the etiology of psychopathy and sociopathy. Neuroscience and Biobehavioral Reviews, 37(7), 1254-1296. doi:10.1016/j.neubiorev.2013.04.009.

Young, S., Smolen, A., Hewitt, J., Haberstick, B., Stallings, M., Corley, R., \& Crowley, T. (2006). Interaction between MAO$A$ genotype and maltreatment in the risk for conduct disorder: Failure to confirm in adolescent patients. American Journal of Psychiatry, 163, 1019-1025. doi:10.1176/appi.ajp.163.6.1019. 